Published in final edited form as:

Ann Biomed Eng. 2010 June ; 38(6): 2167-2182. doi:10.1007/s10439-010-0028-0.

\title{
Osteochondral Interface Tissue Engineering Using Macroscopic Gradients of Bioactive Signals
}

\author{
Nathan H. Dormer ${ }^{1}$, Milind Singh ${ }^{2}$, Limin Wang ${ }^{3}$, Cory J. Berkland ${ }^{4,5}$, and Michael S. \\ Detamore ${ }^{5}$ \\ ${ }^{1}$ Bioengineering Program, University of Kansas, Lawrence, KS 66045, USA \\ ${ }^{2}$ Department of Bioengineering, Rice University, Houston, TX 77005, USA \\ ${ }^{3}$ Department of Biomedical Engineering, University of Michigan, Ann Arbor, MI 48109, USA \\ ${ }^{4}$ Department of Pharmaceutical Chemistry, University of Kansas, Lawrence, KS 66045, USA \\ ${ }^{5}$ Department of Chemical and Petroleum Engineering, University of Kansas, 1530 W 15th Street, \\ 4132 Learned Hall, Lawrence, KS 66045, USA
}

\begin{abstract}
Continuous gradients exist at osteochondral interfaces, which may be engineered by applying spatially patterned gradients of biological cues. In the present study, a protein-loaded microspherebased scaffold fabrication strategy was applied to achieve spatially and temporally controlled delivery of bioactive signals in three-dimensional (3D) tissue engineering scaffolds. Bone morphogenetic protein- 2 and transforming growth factor- $\beta_{1}$-loaded poly(D,Llactic- co-glycolic acid) microspheres were utilized with a gradient scaffold fabrication technology to produce microsphere-based scaffolds containing opposing gradients of these signals. Constructs were then seeded with human bone marrow stromal cells (hBMSCs) or human umbilical cord mesenchymal stromal cells (hUCMSCs), and osteochondral tissue regeneration was assessed in gradient scaffolds and compared to multiple control groups. Following a 6-week cell culture, the gradient scaffolds produced regionalized extracellular matrix, and outperformed the blank control scaffolds in cell number, glycosaminoglycan production, collagen content, alkaline phosphatase activity, and in some instances, gene expression of major osteogenic and chondrogenic markers. These results suggest that engineered signal gradients may be beneficial for osteochondral tissue engineering.
\end{abstract}

\section{Keywords}

Osteochondral; Interface; Gradient; Microsphere; Umbilical cord stem cells; PLGA; BMP-2; TGF- $\beta_{1}$ 


\section{INTRODUCTION}

Spatial patterning of biological cues is vital to some of the most fundamental aspects of life, from embryogenesis, to wound healing, to nerve cell signaling; all involve concentration gradients of signaling molecules. Gradient-based signal delivery strategies have so far gained the most attention in the fields of neural tissue engineering $11,15,27$ and in the study of chemotaxis. ${ }^{10,29}$ Continuous gradient-based bioactive signal delivery systems have seldom been applied in the area of interfacial tissue regeneration. While various strategies have been developed to create gradients of bioactive signals (see review ${ }^{47}$ ), a major limitation with many of these techniques is that they allow the delivery of only haptotactic cues via gelbased substrates. Integration of controlled release technology with graded- signal delivery from macroporous polymeric scaffolds may be a valuable tool in regenerative medicine. Moreover, such interfacial tissue engineering strategies also address a biomimetic approach towards tissue regeneration, where regeneration of a tissue may be enhanced by the presence of endogenous signals provided by the neighboring tissue. ${ }^{18}$ Furthermore, using gradients of multiple bioactive factors, multiple tissue regeneration can be addressed via a single cell source, where, for example, stem cells can be differentiated along different lineages within the same constructs.

From the perspective of osteochondral tissue engineering, an in vitro study reported that only co-culture with chondrocytes (as opposed to fibroblasts or osteoblasts) was successful at promoting osteogenic differentiation of mesenchymal stem cells in a selective manner, ${ }^{18}$ indicating the importance of simultaneous triggering of osteo- and chondro-induction for osteochondral tissue regeneration. An integrated scaffold with embedded gradients of growth factors at the interface may trigger simultaneous tissue formation, and may have a synergistic effect on tissue regeneration. For osteochondral tissue engineering, there are only a few previous reports of scaffold designs having a heterogeneous distribution of growth factors embedded within an integrated scaffold. ${ }^{20,23,24} \mathrm{~A}$ recent study investigated the release of bone morphogenetic protein (BMP)-2 and insulin-like growth factor (IGF)-1 inside poly(D,L-lactic-co-glycolic acid) (PLGA) and silk fibroin microspheres, suspended in a gradient pattern, inside alginate gels. ${ }^{60}$ Another study reported a gradient-gene delivery strategy, where a zonal organization of osteoblastic and fibroblastic cellular phenotypes was engineered in a single construct for the purposes of interfacial tissue engineering. ${ }^{40}$ To the best of our knowledge, continuous gradient-based signal delivery from microparticles alone has never before been applied in the area of osteochondral tissue engineering.

Microsphere-based tissue engineering scaffold designs have gained increasing interest over the past few years. ${ }^{39,45,57,60}$ Utilizing microspheres as the building block of a scaffold offers several benefits, which include the ease of fabrication, control over morphology and physicochemical characteristics, and versatility of controlling the release kinetics of encapsulated factors. ${ }^{5}$ The properties of a scaffold, in turn, can be tailored by altering the microsphere design. For example, the pore size and porosity of a scaffold at micro-levels can be made application-specific by altering the size or changing the interior morphology of the microspheres. ${ }^{7,8}$ Similarly, macromechanical properties and degradability can be altered with the selection of the raw material. To design biodegradable matrices, PLGA, an aliphatic a-hydroxy polyester, is one of the most widely used polymers that has been approved for use in several products. The polymer also offers flexibility in the degradation kinetics, modulated by altering one or more factors, such as molecular weight, co-polymer ratio, tacticity, crystallinity, etc. ${ }^{53,61}$

The goal of the present study was the integration of controlled release technology with a gradient scaffold fabrication strategy, where microsphere-based scaffolds containing opposing gradients of chondrogenic and osteogenic factors were fabricated using 
monodisperse protein-loaded microspheres and an ethanol sintering method. TGF- $\beta_{1}$ is widely known for inducing chondrogenesis, ${ }^{14,21,54}$ as BMP-2 is for osteogenesis. ${ }^{30,38,54}$ In addition, the two proteins can also have mutually inductive effects on differentiation, ${ }^{31,50}$ such as forming the hypertrophic chondrocyte region at the osteochondral interface. The current study attempted to employ the different efficacies of the proteins, where endogenous concentrations of BMP- 2 can be several times greater than those used for TGF- $\beta_{1}$ during in vitro studies. A modest BMP-2/TGF- $\beta_{1}$ ratio of 2:1 was chosen with future in vivo studies in consideration, where avoiding systemic toxicity of growth factors will be important. The constructs were utilized for osteochondral tissue engineering using bone marrow stromal cells (hBMSCs) and human umbilical cord mesenchymal stromal cells (hUCMSCs). There is a growing interest in hUCMSCs as a mesenchymal stem cell source, as they have been shown to have osteogenic, ${ }^{2,25,28,33,58,65}$ chondrogenic, ${ }^{2,28,55,59}$ cardiogenic, ${ }^{55,62}$ and adipogenic ${ }^{2,28,33,62}$ potential. This study evaluated for the first time the performance of these cells in simultaneous osteogenic and chondrogenic (osteochondral) differentiation, and compared their performance to hBMSCs.

\section{MATERIALS AND METHODS}

\section{Scaffolding Materials}

Poly(D,L-lactide-co-glycolic acid) copolymer (PLGA; 50:50 lactic acid : glycolic acid, acid end group, $\mathrm{MW} \sim 42,000-44,000 \mathrm{Da}$ ) of intrinsic viscosity (i.v.) $0.36-0.37 \mathrm{dL} / \mathrm{g}$ was purchased from Lakeshore Biomaterials (Birmingham, AL). Poly(vinyl alcohol) (PVA; 88\% hydrolyzed, 25,000 Da) was obtained from Polysciences, Inc. (Warrington, PA). Transforming growth factor (TGF)- $\beta_{1}$ and BMP-2 were purchased from Peprotech, Inc. (Rocky Hill, NJ).

\section{Preparation of Protein-loaded Microspheres}

BMP-2 was reconstituted in $10 \mathrm{mg} / \mathrm{mL}$ bovine serum albumin (BSA) in phosphate buffered saline (PBS) (both from Sigma, St. Louis, MO). TGF- $\beta_{1}$ was reconstituted in $1 \mathrm{mg} / \mathrm{mL}$ BSA in PBS. The reconstituted protein solutions were individually mixed with PLGA dissolved in dichloromethane (DCM) $(20 \% \mathrm{w} / \mathrm{v})$ at a loading ratio of $10 \mathrm{ng}$ TGF- $\beta_{1}$ or $20 \mathrm{ng}$ BMP-2 per $1.0 \mathrm{mg}$ of PLGA. The final mixture was then sonicated over ice (50\% amplitude, $20 \mathrm{~s}$ ). Using PLGA-protein emulsions, uniform protein-loaded PLGA microspheres were prepared using technology from our previous reports. ${ }^{4,49}$ Briefly, using acoustic excitation produced by an ultrasonic transducer, regular jet instabilities were created in the polymer stream that produced uniform polymer droplets. An annular carrier non-solvent stream $(0.5 \% \mathrm{w} / \mathrm{v}$ PVA in doubledistilled water, $\mathrm{ddH}_{2} \mathrm{O}$ ) surrounding the droplets was produced using a nozzle coaxial to the needle. The emanated polymer/carrier streams flowed into a beaker containing the non-solvent. Incipient polymer droplets were stirred for 3-4 $\mathrm{h}$ to allow solvent evaporation, which were then filtered and rinsed with $\mathrm{ddH}_{2} \mathrm{O}$ to remove residual PVA, and stored at $-20^{\circ} \mathrm{C}$ (Fig. 1a). Blank control microspheres were prepared in a similar manner, where the protein solution was replaced with an equivalent volume of BSA solution $(1 \mathrm{mg} /$ $\mathrm{mL}$ ). Following $48 \mathrm{~h}$ of lyophilization, the size distribution of microsphere preparations was determined using a Coulter Multisizer 3 (Beckman Coulter Inc., Fullerton, CA) equipped with a $560-\mu \mathrm{m}$ aperture.

\section{Scaffold Fabrication}

Gradient scaffolds were prepared using a technology reported previously. ${ }^{49}$ Briefly, lyophilized protein-loaded microspheres were dispersed in $\mathrm{ddH}_{2} \mathrm{O} 2.5 \% \mathrm{w} / \mathrm{v}$, and separately loaded into two syringes. Each construct in total contained $\sim 50 \mathrm{mg}$ of microspheres. Thus, gradient and biphasic scaffolds each contained $\sim 25 \mathrm{mg}$ of BMP-2-loaded polymer, and $\sim 25$ $\mathrm{mg}$ of TGF- $\beta_{1}$-loaded polymer, the only difference being the physical transition between the 
two bioactive signals. The suspensions were pumped into a cylindrical glass mold $(5.3 \mathrm{~mm}$ diameter, $3.0 \mathrm{~cm}$ in height) in a controlled manner using programmable syringe pumps (PHD 22/2000, Harvard Apparatus, Inc., Holliston, MA). Using a filter (particle retention >3 $\mu \mathrm{m})$ at the bottom of the mold, $\mathrm{ddH}_{2} \mathrm{O}$ was filtered, while the microparticles stacked in the mold until a height of $2.5 \mathrm{~mm}$ was reached (Fig. 1b). The profile for Gradient constructs was linear, where the transition region from TGF- $\beta_{1}$ to BMP- 2 constituted the middle half of the scaffold volume, and the top and bottom quarters contained one growth factor. Using an additional infusion syringe pump and a vacuum pump, a constant level of distilled water was maintained in the mold. The stacked microspheres were then sintered using a $100 \%$ ethanol treatment for $1 \mathrm{~h} .{ }^{49}$ The molds (containing the scaffolds) were freeze-dried for $48 \mathrm{~h}$, then the gradient scaffolds were retrieved and stored at $-20^{\circ} \mathrm{C}$. Blank scaffolds and constructs with a homogenous growth factor content (loaded with either all TGF- $\beta_{1}$ or all BMP-2) were prepared in a similar manner.

\section{Description of Experimental Groups}

For constructs with hUCMSCs, six different groups were investigated: (i) blank scaffolds (no growth factors encapsulated) with microspheres of $\sim 220 \mu \mathrm{m}$ in diameter, (ii) blank scaffolds with microspheres of $\sim 70 \mu \mathrm{m}$ in diameter (to investigate a smaller pore size), (iii) scaffolds loaded with all BMP-2 (homogeneous, no gradient), (iv) scaffolds loaded with all TGF- $\beta_{1}$ (homogeneous, no gradient), (v) scaffolds with a biphasic (sharp interface) transition from "osteogenic" (BMP-2-loaded) to "chondrogenic" (TGF- $\beta_{1}$-loaded), and (vi) a gradient transition between microsphere types. Groups (iii) through (vi) used microspheres with a diameter of $\sim 220 \mu \mathrm{m}$. For constructs with hBMSCs, only blank scaffolds were compared to gradient scaffolds, each with $\sim 220 \mu \mathrm{m}$ microspheres (Fig. 1c).

\section{Cell Seeding and Culture}

hBMSCs (from a 24-year-old, non-smoking male, lot \# PCBM1632) at P1, (i.e., plated once) were purchased from StemCell Technologies (Vancouver, Canada). hUCMSCs were harvested from umbilical cords $(n=2)$ as described previously. ${ }^{58}$ Briefly, human umbilical cord collection and cell harvests were approved by the University of Kansas Human Subjects Committee (KU-Lawrence IRB approval \# 15402, KU Medical Center IRB approval \# 10951). All cords were collected from the University of Kansas Medical Center and processed within $24 \mathrm{~h}$. Cords were first cut into $3-5 \mathrm{~cm}$ pieces, and then vessels were removed from each cord segment. Cord segments were minced and incubated in $0.75 \mathrm{mg} /$ $\mathrm{mL}$ type II collagenase ( $298 \mathrm{U} / \mathrm{mg}$; Worthington Biochemical; Lakewood, NJ) at $37^{\circ} \mathrm{C}$. After a 5-h incubation, the resulting homogenous gelatinous solution was obtained and diluted (1:8) in sterile PBS. The solution was centrifuged, the supernatant was discarded, and cells frozen for future use. Frozen hBMSCs and hUCMSCs were thawed, plated at a density of 4000 cells $/ \mathrm{cm}^{2}$ and cultured. The culture medium for both hBMSCs and hUCMSCs consisted of Dulbecco's Modified Eagle medium (DMEM; low glucose), 1\% penicillin-streptomycin (P/S), and 10\% fetal bovine serum (FBS-MSC quantified) (all from Invitrogen Life Technologies, Carlsbad, CA). When 80-90\% confluent, the cells were trypsinized and re-plated at the same plating density. Scaffolds (diameter $5.3 \mathrm{~mm}$, height 2.5 $\mathrm{mm}$ ) were sterilized using ethylene oxide, and placed in a 48 well plate. For gradient and biphasic constructs, the osteogenic side was placed on the bottom (i.e., resting on the well plate surface). It was assumed that orientation would have no significant effect on results. Cells (P4) were re-suspended at a concentration of $10 \times 10^{6}$ cells $/ \mathrm{mL}$. Approximately $28 \mu \mathrm{L}$ ( $50 \%$ of the scaffold volume, approximately corresponding to the pore volume ${ }^{49}$ ) of cell solution was placed directly onto the top of the scaffold, which was soaked into the scaffold via capillary action. Cells were allowed to attach to the scaffolds for $2 \mathrm{~h}$, which was denoted as "week 0." Then, $1.5 \mathrm{mLof}$ a defined medium was added and the scaffolds were cultured statically. Up to day 3, the defined medium consisted of DMEM(low glucose), 1\% P/S, 1X 
Insulin-Transferrin-Selenium (ITS)-premix (BD Biosciences, San Jose, CA), $40 \mu \mathrm{g} / \mathrm{mLL}$ proline (Sigma), $100 \mu \mathrm{M}$ sodium pyruvate (Fisher Scientific, Pittsburgh, PA), and $50 \mu \mathrm{g} / \mathrm{mL}$ L-ascorbic acid (Sigma). $1.0 \mathrm{~mL}$ of the $1.5 \mathrm{~mL}$ was refreshed twice daily for the first 3 days. Following day 3 , the defined culture medium was supplemented with $4 \mathrm{mM} \beta$ glycerophosphate (disodium salt, pentahydrate; Calbiochem, San Diego, CA) and $100 \mathrm{nM}$ dexamethasone. The rationale was that $\beta$-glycerophosphate may serve more as a tool for calcium phosphate deposition by osteoinduced cells rather than as a direct differentiation signal, and that dexamethasone may facilitate both chondrogenic and osteogenic differentiation. After day $3,1 \mathrm{~mL}$ of the $1.5 \mathrm{~mL}$ was refreshed every $24 \mathrm{~h}$.

\section{Protein Release Profiles}

TGF- $\beta_{1}$ and BMP-2 release (from assembled scaffolds and an equivalent mass of nonsintered microspheres) were measured in PBS at $37{ }^{\circ} \mathrm{C}$ using enzymelinked immunosorbent assay (ELISA) kits (BMP-2 from Peprotech Inc. and TGF- $\beta_{1}$ from BD Biosciences). To guarantee no interference between bioactive factors, constructs made from homogeneous TGF- $\beta_{1}$ - loaded or homogeneous BMP-2-loaded microspheres ( $220 \mu \mathrm{m}$ diameter) were used. Samples of PBS surrounding the scaffolds $(n=3)$ were taken at $12 \mathrm{~h}$, then at $1,2,3,5$, $7,10,14$, and 21 days. Loading efficiencies $(n=3)$ were determined by combining $10 \mathrm{mg}$ of either TGF- $\beta_{1}$ - or BMP-2-loaded microspheres with $50 \mu \mathrm{L}$ dimethyl sulfoxide (DMSO, Sigma) and $950 \mu \mathrm{L}$ of PBS. The samples were vortexed thoroughly, and allowed to sit overnight. The samples were then centrifuged at $20,000 \mathrm{rpm}$ for $30 \mathrm{~min}$ to pellet polymer fragments, and the supernatant tested via ELISA. This procedure was performed for both microspheres, and microspheres sintered with ethanol for $1 \mathrm{~h}$. The percent released from scaffolds and microspheres at each time-point was tabulated compared to the total amount of detected protein in ethanol-treated, or nonethanol-treated microspheres.

\section{Quantitative Polymerase Chain Reaction}

In preparation for RT-PCR, samples $(n=4)$ at 0 and 6 weeks were first homogenized in 1 $\mathrm{mL}$ Trizol reagent (Invitrogen) and the RNA was isolated according to the manufacturer's guidelines. Isolated RNA was converted to cDNA using a TaqMan High Capacity kit (Applied Biosystems, Foster City, CA) in a BioRad ThermoCycler. TaqMan Gene expression assays from Applied Biosystems for collagen type I (Hs00164004_m1), collagen type II (Hs00156568_m1), SRY-box 9 (Sox9, Hs00165814_m1), bone sialoprotein (BSP, Hs00173720_m1), runt-related transcription factor 2 (Runx2, Hs00231692_m1), secreted phosphoprotein 1 (SPP1 or osteopontin, Hs00959010_m1), and glyceraldehyde 3-phosphate dehydrogenase (GAPDH, Hs99999905_m1) were used in conjunction with an Applied Biosystems 7500 Fast Real-time PCR System. A $2^{-\Delta C \mathrm{Ct}}$ method was used to evaluate the relative level of expression for each target gene. ${ }^{32}$ For quantification, the hUCMSC Blank 220 constructs were designated as a calibrator group, and GAPDH expression as an endogenous control.

\section{Biochemical Analyses}

Constructs $(n=4)$ were analyzed for matrix production using biochemical assays at 0,3 , and 6 weeks. At week 0, only hUCMSC Blank 220, Blank 70, and hBMSC Blank 220 scaffolds were analyzed for biochemical content. First, a digestion solution consisting of $125 \mu \mathrm{g} / \mathrm{mL}$ papain (from papaya latex, Sigma), $5 \mathrm{mM} \mathrm{N}$-acetyl cysteine, $5 \mathrm{mM}$ ethylenediaminetetraacetic acid (EDTA), and $100 \mathrm{mM}$ potassium phosphate buffer $(20 \mathrm{mM}$ monobasic potassium phosphate, $79 \mathrm{mM}$ dibasic potassium phosphate in $\mathrm{ddH}_{2} \mathrm{O}$ ) in $\mathrm{ddH}_{2} \mathrm{O}$ was mixed (all reagents from Sigma). Constructs were removed from culture in a sterile manner, placed in microcentrifuge tubes, homogenized with the papain mixture, and allowed to digest overnight in a $60^{\circ} \mathrm{C}$ water bath. The digested scaffolds were then centrifuged at $10,000 \mathrm{rpm}$ for $5 \mathrm{~min}$ to pellet fragments of polymer and other impurities, and stored at -20 
${ }^{\circ} \mathrm{C}$. Later, the supernatant was used to determine DNA, glycosaminoglycan (GAG), and hydroxyproline (HYP) content. DNA content was quantified using the Picogreen assay (Molecular Probes, Eugene, OR) according to the manufacturer's instructions. A conversion factor of $8.5 \mathrm{pg} / \mathrm{cell}$, based on earlier preliminary studies, may be used to convert DNA content to cell number. GAG content was measured using a dimethylmethylene blue (DMMB) assay as recommended by the vendor (Biocolor, Newtownabbey, Northern Ireland). Alkaline phosphatase (ALP) activity was determined at $0,1,2,3$, and 6 weeks, and expressed as a measure of liberated $p$-nitrophenol concentration $/ \mu \mathrm{g}$ protein/min, as described elsewhere. ${ }^{9}$ Net HYP content was assessed using a modified hydroxyproline assay ${ }^{16}$ as described in our previous publications. ${ }^{59} \mathrm{~A}$ conversion factor of 11.5 can be used to convert HYP mass to collagen mass based on our preliminary studies. In the cases of GAG and HYP content, results for overall biochemical production and normalized content were analyzed.

\section{Histological Staining}

At 3 and 6 weeks, samples $(n=3)$ were allowed to equilibrate at $37^{\circ} \mathrm{C}$ in optimal cutting temperature embedding medium (OCT, Tissue-Tek) overnight, then frozen at $-20^{\circ} \mathrm{C}$, sectioned at $14 \mu \mathrm{m}$ parallel to the construct axis (Fig. 2) using a cryostat, and collected on SuperFrost Plus slides (Fisher Scientific). Safranin-O/Fast Green staining for GAGs and Alizarin Red staining for calcium deposition was done as described elsewhere. ${ }^{1}$ Slides were then dehydrated in graded alcohol and cleared in xylene for mounting.

\section{Mechanical Testing}

Mechanical characterization of the constructs $(n=4)$ was performed using a uniaxial testing apparatus (Instron Model 5848, Canton, MA, $50 \mathrm{~N}$ load cell) under unconfined compression. Tare-loaded $(0.05 \mathrm{~N})$ constructs were compressed to $15 \%$ strain at a rate of $1 \%$ per second under PBS (138 mM sodium chloride, $2.7 \mathrm{mM}$ potassium chloride) at $37^{\circ} \mathrm{C}$, followed by stress relaxation at $15 \%$ strain for $30 \mathrm{~min}$. Moduli of elasticity were obtained from the linear regions of the stress-strain curves. Relaxed moduli were calculated as the ratio of the final stress value (at the end of $30 \mathrm{~min}$ ) to the step strain. The stress was defined as the ratio of the load to the initial crosssectional area, and the strain was defined as the ratio of the change in the length to the original length. ${ }^{49}$ Mechanical testing was performed on hBMSC Blank constructs at week 0, and on hBMSC Blank and Gradient constructs at week 6. It was assumed that growth factor incorporation would not have a detectable effect on mechanical properties or tissue formation at week 0 , thus the Gradient was only tested at 6 weeks.

\section{Statistical Analyses}

Statistical analyses were performed using a single factor analysis of variance (ANOVA) in SPSS/PASW 17.0 software (SPSS Incorporated, Chicago, IL), followed by a Tukey's Honestly Significant Difference post hoc test when significance was detected below the $p=$ 0.05 value. All quantitative results (numerical values and representative diagrams) were expressed as the average \pm standard deviation.

\section{RESULTS}

\section{Microspheres and Scaffold Fabrication}

Protein-loaded microspheres having uniform diameter were created using the previously reported Precision Particle Fabrication method. ${ }^{4}$ The microspheres displayed high monodispersity, with a $\sim 220 \mu \mathrm{m}$ nominal diameter for all of the three types of microspheres prepared: BMP-2 loaded "osteogenic" microspheres, TGF- $\beta_{1}$ loaded "chondrogenic" microspheres, and control "blank" microspheres (Fig. 3). Specifically, microsphere sizes in the range of $\sim 220 \mu \mathrm{m}$ were chosen, as it was our hypothesis that pore sizes commensurate 
with this range may be more conducive to cellular infiltration and matrix production. To evaluate this hypothesis, a negative control scaffold exhibiting a smaller pore size (microsphere diameter $\sim 70 \mu \mathrm{m}$ ) was incorporated into the hUCMSC culture (Fig. 3).

Cylindrical gradient scaffolds containing opposing gradients of chondrogenic and osteogenic factors along the axis of the molds were produced, ${ }^{49}$ along with other positive control groups (homogeneously-loaded TGF- $\beta_{1}$ and BMP-2), and scaffolds with a biphasic (sharp) transition from osteogenic to chondrogenic (Fig. 1c). The final scaffolds were $5.3 \mathrm{~mm}$ in diameter, and $2.5 \mathrm{~mm}$ in height, making the scaffold volume $\sim 55 \mu \mathrm{L}$. The porosity of the scaffolds, as determined by previous investigations, ${ }^{49}$ is typically about $41 \%$, as measured by $\mu \mathrm{CT}$ image reconstruction, with pore sizes ranging from $20-120 \mu \mathrm{m} .{ }^{49}$ The scaffolds were then seeded with hBMSCs and hUCMSCs and cultured for a 6-week duration as described previously.

\section{Protein Release}

TGF- $\beta_{1}$ and BMP-2 protein release from scaffolds were monitored for 21 days with ELISA as an approximate indication of the temporal delivery profile. In addition, protein release from microspheres alone was observed to contextualize the effects of ethanol sintering on PLGA during construct fabrication. The loading efficiencies for TGF- $\beta_{1}$ and BMP-2 microspheres were $16.4 \pm 1.7 \%$ and $15.4 \pm 3.0 \%$,respectively. The loading efficiencies for TGF- $\beta_{1}$ and BMP-2 microspheres treated with ethanol for $1 \mathrm{~h}$ were $7.55 \pm 0.58 \%$ and $5.5 \pm$ $1.5 \%$. After day 1 , scaffold formulations had an accelerated rate of release compared to microspheres alone, with up to $20 \%$ of the entrapped protein being liberated by 21 days (Fig. $4)$.

\section{Gene Expression}

All hBMSC and hUCMSC groups expressed BSP during week 0, although there were no statistically significant changes between treatments. hBMSC Blank constructs demonstrated a 35-fold $\left(p<5 \times 10^{-5}\right)$ higher level of expression over the calibrator group (hUCMSC Blank 220), which was indeed significant. BSP expression was not detectable in any experimental group after 6 weeks of culture (data not shown).

Expression of collagen type II was detected in all hBMSC and hUCMSC constructs at week 0 , although there were no statistically significant changes between treatments. Collagen type II expression was not abundant in any of the experimental groups after week 0 (data not shown).

Throughout the culture period, expression of collagen type I was evident in all constructs. Among hUCMSC groups, there were not statistically significant differences between groups or throughout the culture period (Supplemental Fig. 1a). Once again, hBMSCs clearly demonstrated a change in collagen type I expression (Fig. 5a). At week 6, hBMSC Blank 220 constructs showed an increase in gene expression of 1.9 times more than the week 0 value $\left(p<5 \times 10^{-8}\right)$ and 6.2 times the hUCMSC Blank 220 constructs at week $6(p<0.05)$. hBMSC Gradient scaffold expression at week 6 was 1.5 times higher than the hBMSC Blank 220 value at the same time point $\left(p<5 \times 10^{-4}\right), 9.9$ times greater than the hUCMSC Blank 220 group at 6 weeks $\left(p<5 \times 10^{-11}\right)$, and 3.1 times higher than the hBMSC Gradient value at week $0\left(p<5 \times 10^{-11}\right)$.

Osteopontin (OPN) expression was seen in all hBMSC and hUCMSC groups at week 0 (Supplemental Fig. 1b). Among hUCMSC treatments, the only statistically significant change among groups or during culture was a 4.7-fold loss in OPN expression in the Biphasic constructs from week 0 to $6(p<0.001)$. OPN expression levels were not evident at 
6 weeks for hBMSC Blank 220 samples, and barely present in hBMSC Gradient constructs (Supplemental Fig. 1b).

Runx2 expression in hUCMSC groups remained constant (no statistically significant differences) throughout the culture period (Supplemental Fig. 1c). Results for the hBMSC Gradient group were quite the opposite, with expression levels 11.7 times higher than the hUCMSC Blank 220 constructs at week $6(p<0030.001)$ and 3.6 times greater than hBMSC Blank 220 groups at week $0(p<0.05)$ (Fig. 5b).

Like Runx2, Sox9 expression was not significantly different among all hUCMSC groups from week 0 to week 6 (Supplemental Fig. 1d). In contrast to the hUCMSC groups, Sox 9 expression in the hBMSC groups increased over the course of 6 weeks (Fig. 5c). hBMSC Gradient constructs at 6 weeks demonstrated a 31-fold higher gene expression compared to hUCMSCBlank 220 scaffolds at week $6\left(p<5 \times 10^{-5}\right)$, had a 9.5 -fold greater expression than hBMSC Blank 220 constructs at week $0\left(p<5 \times 10^{-5}\right)$, and a 3.8 -fold higher expression compared to hBMSC Blank 220 constructs at week $6(p<0.005)$.

\section{DNA Content}

The overall DNA content for all hUCMSC and hBMSC constructs at least doubled during the 6-week culture period compared to week 0 (Fig. 6). All growth factor-loaded scaffolds had statistically significant increases in DNA content from week 3 to week $6(p<0.05)$, and hUCMSC Chondrogenic, Biphasic, and Gradient scaffolds displayed a higher mean DNA content ( $61-83 \%$ more) per construct compared to the blank scaffolds at 6 weeks ( $p<$ 0.05). Detailed statistics can be found in Supplementary Table 1.

\section{Glycosaminoglycan Content}

The overall GAG content for all constructs increased at least 3 times during the 6 -week culture period compared to week $0\left(p<5 \times 10^{-6}\right)$, with this increase also being statistically significant between weeks 3 and $6\left(p<1 \times 10^{-5}\right)$ (Fig. 7a). At 6 weeks, only hUCMSC Gradient and Biphasic constructs had statistically greater GAG levels ( $\sim 50 \%$ more) than hUCMSC Blank scaffolds at week $6(p<0.05)$. Detailed statistics for the net GAG content can be found in Supplementary Table 1.

The normalized data indicated other significant differences in the treatment groups (Fig. 7b). At week 0, hUCMSC Blank 70 constructs made significantly less GAG/DNA than the hUCMSC Blank 200 group ( $p<0.01$ ). At 3 weeks, hUCMSC Blank 220, Chondrogenic, and Biphasic constructs made less GAG/ DNA than during week $0(p<0.001)$, but the Blank 220 and Blank 70 increased GAG/DNA production by week $6(p<0.05)$. In addition, hUCMSC Gradient constructs made more GAG/DNA (7.5 times greater) at week 3 than hUCMSC Blank 220 constructs $\left(p<1 \times 10^{-4}\right)$. GAG/DNA output on hBMSC groups did not change significantly during the study. According to the normalized data, by 6 weeks, GAG/DNA production on all hUCMSC and hBMSC constructs were not significantly different from each other.

\section{Hydroxyproline Content}

Although HYP content was not evident in hUCMSC constructs at week 0 , it was present by week 3 for all groups, but only the hUCMSC Blank 220, Blank 70, and Gradient constructs demonstrated a significant increase $(p<0.05)$ (Fig. 8a). By 6 weeks, all hUCMSC constructs, except the Chondrogenic group, showed statistically significant increases in HYP content compared to week 0 ( $p<0.005)$. At 6 weeks, hUCMSC Gradient constructs demonstrated $\sim 2$ times more HYP production than the hUCMSC Blank and Biphasic groups $(p<0.01)$, at least 3 times more than hBMSC Blank and Gradient constructs $(p<0.001)$, 
and at least 2 times more than any other group at 6 weeks $(p<0.01)$. HYP production for the hBMSC constructs did not differ significantly between treatments or between time points. Detailed statistics for the net HYP content can be found in Supplementary Table 1.

Normalized data indicated other significant differences in the treatment groups. By 3 weeks, hUCMSC Blank 220, Blank 70, and Gradient constructs made more HYP/DNA than the previous time point $(p<.05)$, but Gradient constructs were the only ones to make significantly more HYP/DNA than the control at that time ( $p<0.01)$ (Fig. 8b). hBMSC constructs demonstrated a more defined pattern, with an increase in HYP/DNA production at week $3\left(p<5 \times 10^{-6}\right)$, and a subsequent decrease at week $6\left(p<5 \times 10^{-5}\right)$. hBMSC Gradient constructs also produced 2 times less HYP/DNA at week 3 than the hBMSC Blank 220 constructs $\left(p<5 \times 10^{-7}\right)$.

\section{Alkaline Phosphatase Activity}

ALP activity for all hUCMSC and hBMSC constructs showed no statistically significant changes until week 3 (Fig. 9). ALP activity at week 3 for hUCMSC Biphasic scaffolds was 15 times larger than the week 0 value $\left(p<1 \times 10^{-4}\right), 6.5$ times larger than the previous week $(p<0.001)$, and was 1.8 times greater than hUCMSC Blank constructs at week $3(p<0.05)$. At week 6, hUCMSC Biphasic scaffolds had greater ALP activity compared to the control at week $6(p<0.01)$. The hUCMSC Gradient group also demonstrated a statistically significant increase overall between week 0 and week 6 ( $p<0.005$ ). It was also noted that ALP activity of the hUCMSC constructs exhibited high standard deviations, compared to hBMSCs scaffolds.

\section{Histological Staining}

Staining for GAG content with Safranin-O/Fast Green, and Alizarin Red for calcium deposition, was done on identical areas of constructs to most accurately analyze characteristics of dual tissue and matrix formation. Supplementary Figure 3a shows tissue formation after 3 weeks of culture in hUCMSC microsphere-based scaffolds. At 3 weeks, all hUCMSC constructs demonstrated some degree of GAG staining near the top, with Osteogenic and Chondrogenic scaffolds having more intense staining in the top region. In addition, Biphasic and Gradient scaffolds appeared to be indiscernible from Blank 220 and Blank 70 scaffolds, with sparse GAG staining located on the top of the scaffold. Cell nuclei, visualized with Harris Hematoxylin, were distributed evenly throughout most constructs, with the exception of the Blank 70 group, which lacked a large cell population inside of the microsphere scaffold. At 3 weeks, hBMSC constructs showed overall staining, arguably less than hUCMSC Blank 220 and Blank 70 scaffolds (Supplemental Fig. 3b). Interestingly, the location of calcium staining at 3 weeks within the hUCMSC constructs correlated strongly with location of GAG staining, but was also present throughout the rest of the constructs. Nodules of calcium staining, however, were most prominent in the hUCMSC Osteogenic group.

By 6 weeks, GAG and calcium staining in hUCMSC constructs was significantly greater than observed at 3 weeks, such that the perimeters of the once-present microspheres were clearly visible within the matrix, with faint counter-staining filling the void space (Fig. 10a). Osteogenic and Gradient groups exhibited large, non-uniform clusters of GAG staining near the top of the constructs, while Blank 220 and Biphasic groups had minimal GAG staining. The Chondrogenic group exhibited nodules of GAG staining throughout the entire construct, while GAG staining in the Blank 70 constructs was less than any other group. As observed at 3 weeks, calcium staining associated heavily with location of glycosaminoglycan staining, but was also evident in other areas of the constructs. Perhaps the most striking representation of a gradient transition between types of tissue matrix was seen in the hBMSC scaffolds at 6 
weeks (Fig. 10b). hBMSC Blank 220 constructs exhibited uniform calcium staining and little GAG staining, whereas hBMSC Gradient constructs had light GAG staining localized to the top and dissipated towards of the center of the construct.

\section{Mechanical Testing}

Following unconfined compression testing, the modulus of elasticity was determined to be $127 \pm 44 \mathrm{kPa}$ for the constructs at week 0 (Supplemental Fig. 2). This value dropped drastically after 6 weeks of culture to $3.3 \pm 1.4 \mathrm{kPa}$ for Blank constructs and to $4.0 \pm 0.4 \mathrm{kPa}$ for Gradient constructs. Similarly, the relaxed moduli decreased from $2.1 \pm 0.8 \mathrm{kPa}$ at week 0 to $1.1 \pm 0.6 \mathrm{kPa}$ for Blank constructs and to $0.9 \pm 0.2 \mathrm{kPa}$ for Gradient constructs. The elastic moduli between Blank and Gradient constructs at week 6 were not statistically different. The same was true for the relaxed moduli between the two groups after the culture period had concluded.

\section{DISCUSSION}

The primary objective of this study was to evaluate the dual signaling with bioactive factors, in the form of a microsphere-based gradient, to address osteochondral interfacial tissue engineering. To the best of our knowledge, this was the first effort to examine simultaneous osteogenic and chondrogenic differentiation of hUCMSCs and hBMSCs on continuously graded 3D scaffolds for interfacial tissue engineering.

A specialized cell culture media was carefully formulated, based on the current literature for inducing chondrogenesis ${ }^{2,28,55}$ and osteogenesis. ${ }^{2,28,33,43,62}$ The circumstances in this experiment, however, were novel in that both of these pathways were being addressed simultaneously, something that is not well characterized. The most logical approach was to ensure that the defined media included essential components for differentiation into either cell type.

The results also confirmed that microsphere degradation released both BMP-2 and TGF- $\beta_{1}$ in a temporal manner (Fig. 4). A classic "burst" release of protein, common to microspherebased delivery, ${ }^{4,5}$ was observed in the first week, allowing delivery of up to $20 \%$ of total entrapped protein from scaffolds by 21 days, during a crucial time when differentiation of the seeded cells was taking place. Most importantly, release most likely extended well beyond this time frame for continuous signal delivery, judging by the onset of third phase of release typically seen in PLGA microparticle delivery. ${ }^{3}$ The accelerated release rate of ethanol-treated microspheres, when compared to microspheres alone, suggests that polymer chain entanglement was altered during sintering. In previous investigations with this design, ${ }^{49}$ it was shown that ethanol treatment lowered the PLGA glass transition temperature from $41.04 \pm 0.17{ }^{\circ} \mathrm{C}$ to $33.98 \pm 0.09^{\circ} \mathrm{C}$. Moreover, at $37^{\circ} \mathrm{C}$ the scaffolds might have exhibited a diminished ability to sequester protein. In addition, the lower entrapment efficiency observed for sintered microspheres was most likely due to a certain fraction of protein near the microsphere surfaces being exposed to ethanol. Ideal endogenous growth factor concentrations may be different from the values achieved during this first attempt, and the need for future investigation of varying loading values will be warranted. Lastly, during cell culture, media was refreshed more frequently than during the release study, thus, the quantity of endogenous growth factors in the well during culture may have varied slightly from the observed release profile. Coupled with an osteochondral medium, many primary factors contributing to osteogenic and chondrogenic differentiation were addressed during culture.

In the current study, major osteogenic and chondrogenic markers were monitored for an indication of how gene expression changed due to dual signal delivery. At week 0, all 
groups expressed collagen I, collagen II, BSP, OPN, Runx2, and Sox9. Perhaps this can only be taken as an indication of the multi-lineage potential of hBMSCs and hUCMSCs. Gene expression in hBMSCs in general was more pronounced than in hUCMSCs. By 6 weeks, BSP and collagen II were not in enough abundance to detect in both hUCMSCs and hBMSCs. During osteogenesis, many genes, including BSP, have fluctuating expression. BSP is most known as a primary non-collagenous protein of mineralized tissues, ${ }^{6,42}$ and if there were to be formation of a bonelike tissue taking place, the absence of BSP at later times may be nothing more than an indication that the matrix is not nearing late-term. Similarly, collagen II is associated with hyaline cartilage, ${ }^{51}$ thus there only may have been some degree of chondrogenic differentiation.

Statistically, there were no differences in the gene expressions of collagen I, Runx2, and Sox9 during the study (Supplemental Fig. 1). Average OPN expression remained unchanged in most hUCMSC and all hBMSC constructs during the culture period, with only one statistically significant decrease, in the hUCMSC Biphasic group (Supplemental Fig. 1b). Initially, this phenomenon seemed counterintuitive, as in some groups osteoblastic-like behavior was desired, with OPN being an extracellular structural protein in bone. ${ }^{42}$ Recent characterizations of hUCMSCs have shown that the umbilical cord stroma has a baseline OPN expression, ${ }^{25}$ and OPN expression during culture may actually significantly decrease in hUCMSCs, regardless of whether receiving an osteogenic treatment. ${ }^{56}$ It has also been suggested that OPN acts in later stages of remodeling by tethering osteoclasts to the mineralized matrix, ${ }^{12,41}$ a phase (bone resorption) that these constructs had not reached.

In some instances, however, hBMSCs clearly demonstrated that a gradient in bioactive signaling had advantages in promoting expression of both osteogenic and chondrogenic markers (Fig. 5). Being the most abundant of the collagens, a statistically significant increase in collagen I alone (from a growth-factor loaded construct) is not necessarily cause for excitement, but coupled with key transcription factors for osteoblast (Runx2) and chondrocyte (Sox9) differentiation ${ }^{19}$ at later culture times, warrants a closer look at the potential of a gradient in bioactive signaling. In this instance, hBMSCs are most likely the superior model for changing gene expression due to the gradient design. This does not necessarily imply that hUCMSCs lack expression of any key osteogenic and chondrogenic markers, just that hBMSCs perhaps tailor a more well-understood quantitative response to growth factor delivery coupled with defined culture conditions. Tests to compare primer sensitivity were not performed in this study, however, previous investigations in osteogenic $^{56,58}$ or chondrogenic ${ }^{59}$ differentiation of hUCMSCs, with RT-PCR techniques and probes identical to the ones used in this study, have not indicated significant detection errors. Future characterizations, including more frequent monitoring of gene expression early in culture, might better delineate the transitory expression of specific genes during differentiation. In addition, including more donors for both hUCMSCs and hBMSCs might minimize variation.

Based on DNA content (Fig. 6), and a conversion factor of $8.5 \mathrm{pg}$ DNA/cell, a cell seeding efficiency of 55\% (hUCMSCs) to 70\% (hBMSCs) was calculated. Thus, there appears to be room for improvement with regard to cell attachment, and methods such as functionalizing the polymer with Arg-Gly-Asp (RGD) residues ${ }^{22,63,64}$ may help. Yet, DNA content saw multiple-factor increases by week 6. By 6 weeks, hUCMSC Chondrogenic, Biphasic, and Gradient groups were the only groups with significantly higher cell content than the control; however, the three treatments were not significantly different from each other. In addition, even though an increase in cell number alluded to proliferation and cell retention, these results alone did not prove proliferation. Moreover, at this time, dual growth factor inclusion could not be misconstrued as a means to definitively increase cell number. 
Overall GAG formation was initially slow to take place in all groups, with statistically significant increases only by the last week of culture (Fig. 7a). Only the dual growth factor groups (hUCMSC Biphasic and Gradient) outperformed their control at that time, suggesting that chondrogenesis may have been enhanced in the presence of both TGF- $\beta_{1}$ and BMP-2. The normalized GAG data showed interesting trends (Fig. 7b). The difference in GAG content per cell between hUCMSC Blank 70 and hUCMSC Blank 220 constructs suggested that a smaller pore size had an effect on some instances of biochemical production, possibly due to the different physical proximities of the cells that had managed to penetrate the scaffold. In addition, the Gradient design might have had advantages in promoting early biochemical output from cells, judging by the increased GAG per cell at week 3. Thus, perhaps only the Gradient design was beneficial for constant increased GAG output per cell, as Blank constructs had fluctuating GAG per cell output. In addition, it appears that hBMSCs were not as sensitive to the Gradient design, as both groups maintained the same level of GAG production during the entire study.

Net HYP content in hUCMSC groups increased at week 3 for the Blank 220, Blank 70, and Gradient groups, with the Osteogenic and Biphasic groups having increased HYP mass at week 6. (Fig. 8a). Because hUCMSCs Chondrogenic constructs failed to have an increase in HYP content during the whole culture, and at 6 weeks, the level was less than the control, the collagen composition might have been different from the other treatment groups. In addition, hUCMSC Blank 220, Blank 70, Osteogenic, and Biphasic constructs were not different from one another with regard to HYP content, and all were significantly less than hUCMSC Gradient constructs in HYP content, at 6 weeks. The normalized data demonstrated a similar advantage of the Gradient constructs, with hUCMSCs in these groups producing at least 2 times more HYP than the Blank 220 and Biphasic groups at 3 weeks (Fig. 8b). The finding of net HYP content at 6 weeks, and HYP content per cell at 3 weeks, being significantly higher in the Gradient constructs than in the Biphasic and Blank 220 constructs was among the most important findings of the current study. The Gradient and Biphasic groups had exactly the same relative numbers of osteogenic and chondrogenic microspheres, but a different spatial organization. Therefore, this significant difference in HYP content demonstrated that taking the same signals and releasing them in opposing gradients, instead of in two adjacent homogeneous regions, could result in a significant improvement in early and overall biosynthesis. Moreover, gradient-based strategies may be beneficial for osteochondral tissue engineering where early neosynthesis of tissue is critical for defect healing and construct integration.

As mentioned, there were no statistically significant changes in ALP activity in hUCMSC or hBMSC scaffolds up until week 3 (Fig. 9). Because ALP isoforms are present in many tissue types ${ }^{37}$ having baseline p-nitrophenol activity in hUCMSCs alone (as in the Blank 220 and Blank 70 constructs) is not surprising. Yet, at 3 weeks and 6 weeks, the hUCMSC Biphasic group showed a statistically significant increase over the control. It is known, however, that during osteogenic differentiation of MSCs, ALP activity decreases at later times, as it is an early indicator of osteogenic differentiation. ${ }^{26}$ The absence of statistically significant decreases in ALP activity in the treatment groups suggests that either osteogenic differentiation might not have taken place yet, or this phenomenon was missed due to spacing between assay time points. Interestingly, an unchanging ALP activity in osteogenic differentiation of hUCMSCs has been observed before, ${ }^{56}$ thus, the reasons for such a discrepancy should be investigated further.

Based on histology, it appeared that having a smaller pore size, as in the hUCMSC Blank 70 group, hindered cellular penetration within the microsphere matrix. Even though this group performed satisfactorily during biochemical production, the majority of this matrix formed around the perimeter of the constructs. In addition, the inclusion of growth factors in general 
appeared to enhance both GAG formation and calcium deposition. GAG formation sometimes occurred in small nodes on the top side of the scaffold, rather than evenly throughout the construct. Furthermore, a small amount of tissue production in hUCMSC constructs might be localized to the side of the scaffold that cell seeding took place, not necessarily to growth factor location, despite most constructs (with the exception of the hUCMSC Blank 70 group) having cell penetration throughout the scaffolding (Fig. 10). In addition, calcium deposition overlapped with GAG formation on the scaffold tops, but was also present throughout the constructs in places where GAGs were not. The significant calcium deposition in most hUCMSC constructs (along with collagen I expression) could be consistent with recent evidence suggesting that hUCMSCs may be predisposed toward the osteoblast lineage. ${ }^{13}$ Uniform exposure of $\beta$-glycerophosphate and dexamethasone may have contributed to calcium staining observed throughout the constructs, however, uniform exposure of $\beta$-glycerophosphate (or any other culture medium component) would not be an issue as this technology translates to in vivo application. Strategies such as changing the TGF- $\beta_{1} /$ BMP-2 loading ratio, improving protein stability, or changing polymer degradation rate, may improve the results. In hBMSC Blank 220 constructs, there was little GAG formation, and evenly distributed calcium deposition. In contrast to hUCMSC scaffolds, hBMSCs readily demonstrated a histological response to the gradient of growth factors, having light GAG formation near the top of the construct, which faded as it approached the middle. Visualization of a gradient in tissue underscored the importance of improving and refining this technology.

The drastic drop in the mechanical integrity of the constructs was most likely a consequence of microsphere degradation that led to the disappearance of the sintering sites with time, transitioning to the mechanical integrity of the neo-synthesized tissue (Supplemental Fig. 2). To improve the mechanical stiffness of the constructs, one method could be to utilize microspheres with encapsulated nanomaterials such as calcium carbonate $\left(\mathrm{CaCO}_{3}\right),{ }^{17,48}$ titanium dioxide $\left(\mathrm{TiO}_{2}\right),{ }^{34,48,52}$ or hydroxyapatite (HAp). The inclusion of HAp, especially in vivo, may also enhance osteoblastic behavior and osseointegration as seen in other tissue engineering $35,36,44$ and microsphere ${ }^{45,46}$ applications. As of now, the focus on comprehensive tissue regeneration is of utmost importance, but later in development, in clinical cases where osteochondral defects are large, mechanical stiffness will become a substantial priority, and the gradient strategy described here will be highly conducive to incorporating stiffness gradients as well, as recently outlined. ${ }^{48}$

Lastly, we acknowledge that the gradients cannot be sustained for a long duration in the in vitro culture environment, and released growth factors in soluble form will eventually diffuse unless they are consumed by the cells. To maintain the gradient profiles during the culture, the media was refreshed twice a day for first 3 days (a crucial period for cell differentiation) and then daily afterwards. This unconventional media refreshment frequency was applied to mitigate the effects of growth factor diffusion and maintain the spatial profiles of growth factors during the in vitro culture period. One can envision that growth factor diffusion will be a lesser concern in vivo, where diffusion of the factors will be restrained in a confined environment (as in the case of a defect repair) and in the absence of cell culture media. Follow-up in vivo work will give insight about this hypothesis.

Future work should include evaluation of higher growth factor concentrations, surface functionalization Osteochondral Interface Tissue Engineering 2179 for cell attachment, and accelerated scaffold degradation. Given that the current study was a proof of concept for the feasibility of the approach and the large-scale effects on the entire scaffolds, gradient transitions were monitored only histologically. With evidence from histology and total collagen content suggesting that gradients have the potential to improve efficacy and lead to regionalized tissue formation, examination of regional biochemical content, 
immunohistochemistry, and gene expression will be warranted in the future. ${ }^{19}$ In situ hybridization will also allow visualization of region-specific gene expression, as tracking cell populations will be instrumental in refining the spatiotemporal characteristics of the gradient for hUCMSCs, hBMSCs, and other stem cell types.

\section{CONCLUSION}

One must consider the progression of these two stem cell types toward the desired lineages, with hBMSCs starting further along in their "journey" to produce bone and cartilage matrix and express the proper osteoblast and chondrocyte phenotypes. Consequently, the response to growth factors and culture conditions is cell-specific. With the data presented here, it was clear that both cell types had their distinct strengths. The hBMSC response to the Gradient design in protein signaling was well defined within their gene expression, but the actual biochemical performance by hBMSCs was not especially significant compared to hUCMSCs. Yet, biochemical activity from hUCMSCs came with larger variations between samples, and their ability to meaningfully localize the significant matrix produced was inferior to hBMSCs, which indicated that further investigation will be needed to more accurately control hUCMSC differentiation. Cellular idiosyncrasies aside, the merit of using macroscopic gradients for osteochondral interfacial tissue engineering in vitro was demonstrated in many key ways. With the proof-of-concept established here, it may stand to reason that the gradient-based scaffolds will be well suited for in vivo application, with a support structure to facilitate a continuous transition of bone regeneration to cartilage regeneration.

\section{Supplementary Material}

Refer to Web version on PubMed Central for supplementary material.

\section{Acknowledgments}

The authors would like to express their gratitude to the Arthritis Foundation, the National Institutes of Health (NIH/ NIDCR 1 R21 DE017673-01) for their support, to NIGMS/NIH Pharmaceutical Aspects of Biotechnology Training grant (T32-GM008359) for supporting N. H. Dormer, and to Dr. Xinkun Wang of the K.U. Genomics Facility for his guidance in RT-PCR.

\section{REFERENCES}

1. An, Y.; Martin, K. Humana Press; 2003. Handbook of Histology Methods for Bone and Cartilage.

2. Baksh D, Yao R, Tuan RS. Comparison of proliferative and multilineage differentiation potential of human mesenchymal stem cells derived from umbilical cord and bone marrow. Stem Cells. 2007; 25:1384-1392. [PubMed: 17332507]

3. Batycky R, Hanes J, Langer R, Edwards D. A theoretical model of erosion and macromolecular drug release from biodegrading microspheres. J. Pharm. Sci. 1997; 86:1464-1477. [PubMed: 9423163]

4. Berkland C, Kim K, Pack DW. Fabrication of PLG microspheres with precisely controlled and monodisperse size distributions. J. Controlled Rel. 2001; 73:59-74.

5. Berkland C, Kim K, Pack DW. PLG microsphere size controls drug release rate through several competing factors. Pharm. Res. 2003; 20:1055-1062. [PubMed: 12880292]

6. Bianco P, Fisher L, Young M, Termine J, Robey P. Expression of bone sialoprotein (BSP) in developing human tissues. Calcif. Tissue Int. 1991; 49:421-426. [PubMed: 1818768]

7. Botchwey EA, Pollack SR, El-Amin S, Levine EM, Tuan RS, Laurencin CT. Human osteoblast-like cells in three-dimensional culture with fluid flow. Biorheology. 2003; 40:299-306. [PubMed: 12454419] 
8. Botchwey EA, Pollack SR, Levine EM, Laurencin CT. Bone tissue engineering in a rotating bioreactor using a microcarrier matrix system. J. Biomed. Mater. Res. 2001; 55:242-253. [PubMed: 11255176]

9. Boyan BD, Schwartz Z, Bonewald LF, Swain LD. Localization of 1,25-(OH)2D3-responsive alkaline phosphatase in osteoblast-like cells (ROS 17/2.8, MG 63, and MC 3T3) and growth cartilage cells in culture. J. Biol. Chem. 1989; 264:11879-11886. [PubMed: 2545688]

10. Boyden S. The chemotactic effect of mixtures of antibody and antigen on polymorphonuclear leucocytes. J. Exp. Med. 1962; 115:453-466. [PubMed: 13872176]

11. Cao X, Shoichet MS. Investigating the synergistic effect of combined neurotrophic factor concentration gradients to guide axonal growth. Neuroscience. 2003; 122:381-389. [PubMed: 14614904]

12. Choi S, Kim J, Kang E, Lee S, Park M, Park Y, Lee S. Osteopontin might be involved in bone remodelling rather than in inflammation in ankylosing spondylitis. Rheumatology. 2008; 47:17751779. [PubMed: 18854347]

13. Ciavarella S, Dammacco F, De Matteo M, Loverro G, Silvestris F. Umbilical cord mesenchymal stem cells: role of regulatory genes in their differentiation to osteoblasts. Stem Cells Dev. 2009; 18:1211-1220. [PubMed: 19125623]

14. Dickhut A, Dexheimer V, Martin K, Lauinger R, Heisel C, Richter W. Chondrogenesis of human mesenchymal stem cells by local TGF-beta delivery in a biphasic resorbable carrier. Tissue Eng. A. 2010; 16(2):453-464.

15. Dodla MC, Bellamkonda RV. Anisotropic scaffolds facilitate enhanced neurite extension in vitro. J. Biomed. Mater. Res. A. 2006; 78:213-221. [PubMed: 16892507]

16. Edwards C, O'Brien W Jr. Modified assay for determination of hydroxyproline in a tissue hydrolyzate. Clin. Chim. Acta. 1980; 104:161-167. [PubMed: 7389130]

17. Eufinger H, Rasche C, Lehmbrock J, Wehmoller M, Weihe S, Schmitz I, Schiller C, Epple M. Performance of functionally graded implants of polylactides and calcium phosphate/calcium carbonate in an ovine model for computer assisted craniectomy and cranioplasty. Biomaterials. 2007; 28:475-485. [PubMed: 16996127]

18. Gerstenfeld LC, Cruceta J, Shea CM, Sampath K, Barnes GL, Einhorn TA. Chondrocytes provide morphogenic signals that selectively induce osteogenic differentiation of mesenchymal stem cells. J. Bone Miner. Res. 2002; 17:221-230. [PubMed: 11811552]

19. Gordeladze J, Djouad F, Brondello J, Noël D, Duroux-Richard I, Apparailly F, Jorgensen C. Concerted stimuli regulating osteo-chondral differentiation from stem cells: phenotype acquisition regulated by microRNAs. Acta Pharmacol. Sin. 2009; 30:1369-1384. [PubMed: 19801995]

20. Guo X, Park H, Liu G, Liu W, Cao Y, Tabata Y, Kasper FK, Mikos AG. In vitro generation of an osteochondral construct using injectable hydrogel composites encapsulating rabbit marrow mesenchymal stem cells. Biomaterials. 2009; 30:2741-2752. [PubMed: 19232711]

21. Heng BC, Cao T, Lee EH. Directing stem cell differentiation into the chondrogenic lineage in vitro. Stem Cells. 2004; 22:1152-1167. [PubMed: 15579636]

22. Hersel U, Dahmen C, Kessler H. RGD modified polymers: biomaterials for stimulated cell adhesion and beyond. Biomaterials. 2003; 24:4385-4415. [PubMed: 12922151]

23. Holland TA, Bodde EW, Baggett LS, Tabata Y, Mikos AG, Jansen JA. Osteochondral repair in the rabbit model utilizing bilayered, degradable oligo(poly (ethylene glycol) fumarate) hydrogel scaffolds. J. Biomed. Mater. Res. A. 2005; 75:156-167. [PubMed: 16052490]

24. Holland TA, Bodde EW, Cuijpers VM, Baggett LS, Tabata Y, Mikos AG, Jansen JA. Degradable hydrogel scaffolds for in vivo delivery of single and dual growth factors in cartilage repair. Osteoarthr. Cartil. 2007; 15:187-197. [PubMed: 16965923]

25. Hou T, Xu J, Wu X, Xie Z, Luo F, Zhang Z, Zeng L. Umbilical cord Wharton's Jelly: a new potential cell source of mesenchymal stromal cells for bone tissue engineering. Tissue Eng. A. 2009; 15:2325-2334.

26. Jaiswal N, Haynesworth SE, Caplan AI, Bruder SP. Osteogenic differentiation of purified, cultureexpanded human mesenchymal stem cells in vitro. J. Cell. Biochem. 1997; 64:295-312. [PubMed: 9027589] 
27. Kapur TA, Shoichet MS. Immobilized concentration gradients of nerve growth factor guide neurite outgrowth. J. Biomed. Mater. Res. 2004; 68:235-243.

28. Karahuseyinoglu S, Cinar O, Kilic E, Kara F, Akay GG, Demiralp DO, Tukun A, Uckan D, Can A. Biology of stem cells in human umbilical cord stroma: in situ and in vitro surveys. Stem Cells. 2007; 25:319-331. [PubMed: 17053211]

29. Knapp DM, Helou EF, Tranquillo RT. A fibrin or collagen gel assay for tissue cell chemotaxis: assessment of fibroblast chemotaxis to GRGDSP. Exp. Cell Res. 1999; 247:543-553. [PubMed: 10066382]

30. Knippenberg M, Helder MN, Zandieh Doulabi B, Wuisman PIJM, Klein-Nulend J. Osteogenesis versus chondrogenesis by BMP-2 and BMP-7 in adipose stem cells. Biochem. Biophys. Res. Commun. 2006; 342:902-908. [PubMed: 16500625]

31. Kramer J, Hegert C, Guan K, Wobus AM, Müller PK, Rohwedel J. Embryonic stem cell-derived chondrogenic differentiation in vitro: activation by BMP-2 and BMP-4. Mech. Dev. 2000; 92:193205. [PubMed: 10727858]

32. Livak KJ, Schmittgen TD. Analysis of relative gene expression data using real-time quantitative PCR and the 2(-Delta Delta C(T)) method. Methods. 2001; 25:402-408. [PubMed: 11846609]

33. Lu LL, Liu YJ, Yang SG, Zhao QJ, Wang X, Gong W, Han ZB, Xu ZS, Lu YX, Liu D, Chen ZZ, Han ZC. Isolation and characterization of human umbilical cord mesenchymal stem cells with hematopoiesis-supportive function and other potentials. Haematologica. 2006; 91:1017-1026. [PubMed: 16870554]

34. Lu X, Lv X, Sun Z, Zheng Y. Nanocomposites of poly(l-lactide) and surface-grafted $\mathrm{TiO}_{2}$. nanoparticles: synthesis and characterization. Eur. Polym. J. 2008; 44:2476-2481.

35. Luiz Meirelles LM, Peltola T, Kjellin P, Kangasniemi I, Currie F, Andersson M, Albrektsson T, Wennerberg A. Effect of hydroxyapatite and titania nanostructures on early in vivo bone response. Clin.Implant Dentist. Rel. Res. 2008; 10:245-254.

36. Matthias W, Laschke KW, Pohlemann T, Menger MD. Injectable nanocrystalline hydroxyapatite paste for bone substitution: in vivo analysis of biocompatibility and vascularization. J. Biomed.Mater. Res. B. 2007; 82B:494-505.

37. Moss D. Alkaline phosphatase isoenzymes. Clin. Chem. 1982; 28:2007-2016. [PubMed: 6751596]

38. Noël D, Gazit D, Bouquet C, Apparailly F, Bony C, Plence P, Millet V, Turgeman G, Perricaudet M, Sany J, Jorgensen C. Short-term BMP-2 expression is sufficient for in vivo osteochondral differentiation of mesenchymal stem cells. Stem Cells. 2004; 22:74-85. [PubMed: 14688393]

39. Petrie Aronin CE, Sadik KW, Lay AL, Rion DB, Tholpady SS, Ogle RC, Botchwey EA. Comparative effects of scaffold pore size, pore volume, and total void volume on cranial bone healing patterns using microsphere-based scaffolds. J. Biomed. Mater. Res. A. 2009; 89:632-641. [PubMed: 18442122]

40. Phillips JE, Burns KL, Le Doux JM, Guldberg RE, Garcia AJ. Engineering graded tissue interfaces. Proc. Natl. Acad. Sci. USA. 2008; 105:12170-12175. [PubMed: 18719120]

41. Reinholt F, Hultenby K, Oldberg A, Heinegård D. Osteopontin-a possible anchor of osteoclasts to bone. Proc. Natl. Acad. Sci. 1990; 87:4473-4475. [PubMed: 1693772]

42. Ross F, Chappel J, Alvarez J, Sander D, Butler W, Farach-Carson M, Mintz K, Robey P, Teitelbaum S, Cheresh D. Interactions between the bone matrix proteins osteopontin and bone sialoprotein and the osteoclast integrin alpha v beta 3 potentiate bone resorption. J. Biol. Chem. 1993; 268:9901-9907. [PubMed: 8486670]

43. Sarugaser R, Lickorish D, Baksh D, Hosseini MM, Davies JE. Human umbilical cord perivascular (HUCPV) cells: a source of mesenchymal progenitors. Stem Cells. 2005; 23:220-229. [PubMed: 15671145]

44. Scaglione S, Ilengo C, Fato M, Quarto R. Hydroxyapatite-coated polycaprolactone wide mesh as a model of open structure for bone regeneration. Tissue Eng. A. 2009; 15:155-163.

45. Shen H, Hu X, Yang F, Bei J, Wang S. An injectable scaffold: rhBMP-2-loaded poly (lactide-coglycolide)/hydroxyapatite composite microspheres. Acta Biomater. 2009

46. Shi X, Wang Y, Ren L, Gong Y, Wang D. Enhancing alendronate release from a novel PLGA/ hydroxyapatite microspheric system for bone repairing applications. Pharm. Res. 2009; 26:422430. [PubMed: 18979188] 
47. Singh M, Berkland C, Detamore MS. Strategies and applications for incorporating physical and chemical signal gradients in tissue engineering. Tissue Eng. B. 2008; 14:341-366.

48. Singh M, Dormer N, Salash J, Christian J, Moore D, Berkland C, Detamore M. Three-dimensional macroscopic scaffolds with a gradient in stiffness for functional regeneration of interfacial tissues. J. Biomed. Mater. Res. A. 2010 Available online ahead of print,

49. Singh M, Morris CP, Ellis RJ, Detamore MS, Berkland C. Microsphere-based seamless scaffolds containing macroscopic gradients of encapsulated factors for tissue engineering. Tissue Eng. C: Methods. 2008; 14:299-309.

50. Spinella-Jaegle S, Roman-Roman S, Faucheu C, Dunn FW, Kawai S, Galléa S, Stiot V, Blanchet AM, Courtois B, Baron R, Rawadi G. Opposite effects of bone morphogenetic protein-2 and transforming growth factor-beta1 on osteoblast differentiation. Bone. 2001; 29:323-330. [PubMed: 11595614]

51. Stokes D, Liu G, Dharmavaram R, Hawkins D. Regulation of type-II collagen gene expression during human chondrocyte de-differentiation and recovery of chondrocyte-specific phenotype in culture involves Sry-type high-mobility-group box (SOX) transcription factors. Biochem. J. 2001; 360:461-470. [PubMed: 11716775]

52. Torres FG, Nazhat SN, Sheikh Md Fadzullah SH, Maquet V, Boccaccini AR. Mechanical properties and bioactivity of porous $\mathrm{PLGA} / \mathrm{TiO}_{2}$ nanoparticle-filled composites for tissue engineering scaffolds. Compos. Sci. Technol. 2007; 67:1139-1147.

53. Tracy MA, Ward KL, Firouzabadian L, Wang Y, Dong N, Qian R, Zhang Y. Factors affecting the degradation rate of poly(lactide-co-glycolide) microspheres in vivo and in vitro. Biomaterials. 1999; 20:1057-1062. [PubMed: 10378806]

54. Tuan RS, Boland G, Tuli R. Adult mesenchymal stem cells and cell-based tissue engineering. Arthritis Res. Ther. 2003; 5:32-45. [PubMed: 12716446]

55. Wang HS, Hung SC, Peng ST, Huang CC, Wei HM, Guo YJ, Fu YS, Lai MC, Chen CC. Mesenchymal stem cells in the Wharton's jelly of the human umbilical cord. Stem Cells. 2004; 22:1330-1337. [PubMed: 15579650]

56. Wang L, Dormer NH, Bonewald L, Detamore MS. Osteogenic differentiation of human umbilical cord mesenchymal stromal cells in polyglycolic acid scaffolds. Tissue Eng. A. 2010 Available online ahead of print,

57. Wang Y, Shi X, Ren L, Wang C, Wang D-A. Porous poly (lactic-co-glycolide) microsphere sintered scaffolds for tissue repair applications. Mater. Sci. Eng. C. 2009; 29:2502-2507.

58. Wang L, Singh M, Bonewald LF, Detamore MS. Signalling strategies for osteogenic differentiation of human umbilical cord mesenchymal stromal cells for 3D bone tissue engineering. J. Tissue Eng. Regen. Med. 2009; 3:398-404. [PubMed: 19434662]

59. Wang L, Tran I, Seshareddy K, Weiss ML, Detamore MS. A comparison of human bone marrowderived mesenchymal stem cells and human umbilical cord-derived mesenchymal stromal cells for cartilage tissue engineering. Tissue Eng. A. 2009; 15:1009-1017.

60. Wang X, Wenk E, Zhang X, Meinel L, Vunjak-Novakovic G, Kaplan D. Growth factor gradients via microsphere delivery in biopolymer scaffolds for osteochondral tissue engineering. J. Controlled Rel. 2009; 134:81-90.

61. Wu L, Ding J. In vitro degradation of three-dimensional porous poly(D, L-lactide-co-glycolide) scaffolds for tissue engineering. Biomaterials. 2004; 25:5821-5830. [PubMed: 15172494]

62. Wu KH, Zhou B, Yu CT, Cui B, Lu SH, Han ZC, Liu YL. Therapeutic potential of human umbilical cord derived stem cells in a rat myocardial infarction model. Ann. Thorac. Surg. 2007; 83:1491-1498. [PubMed: 17383364]

63. Yang X, Roach H, Clarke N, Howdle S, Quirk R, Shakesheff K, Oreffo R. Human osteoprogenitor growth and differentiation on synthetic biodegradable structures after surface modification. Bone. 2001; 29:523-531. [PubMed: 11728922]

64. Zhang H, Hollister S. Comparison of bone marrow stromal cell behaviors on poly (caprolactone) with or without surface modification: studies on cell adhesion, survival and proliferation. J. Biomater. Sci. Polym. Ed. 2009; 20:1975-1993. [PubMed: 19874672] 
65. Zhao L, Burguera EF, Xu HHK, Amin N, Ryou H, Arola DD. Fatigue and human umbilical cord stem cell seeding characteristics of calcium phosphate-chitosanbiodegradable fiber scaffolds. Biomaterials. 2009; 31:840-847. [PubMed: 19850337] 


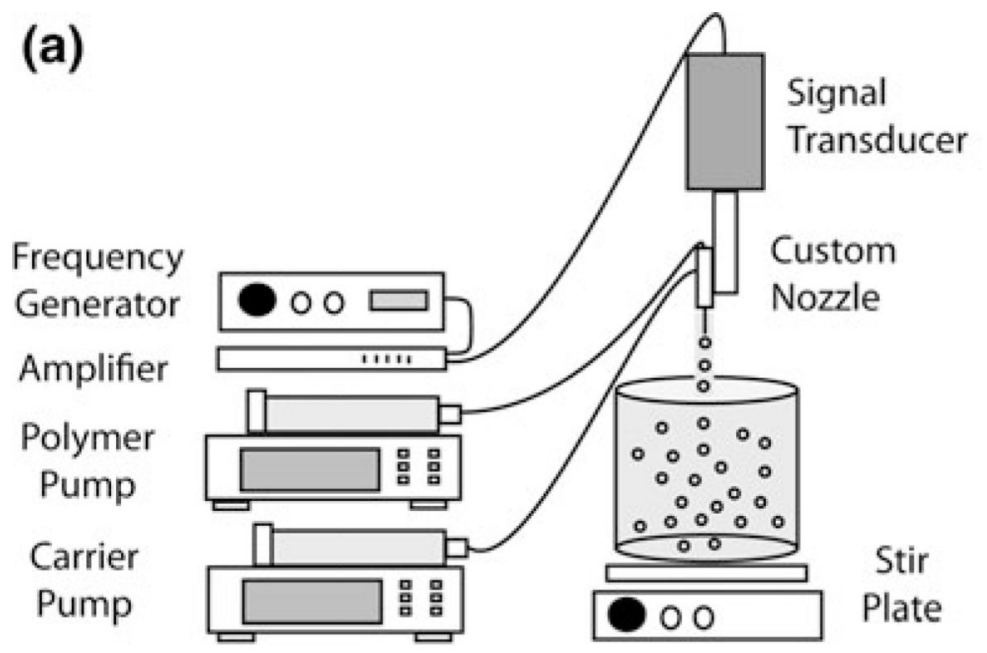

(b)

(c)

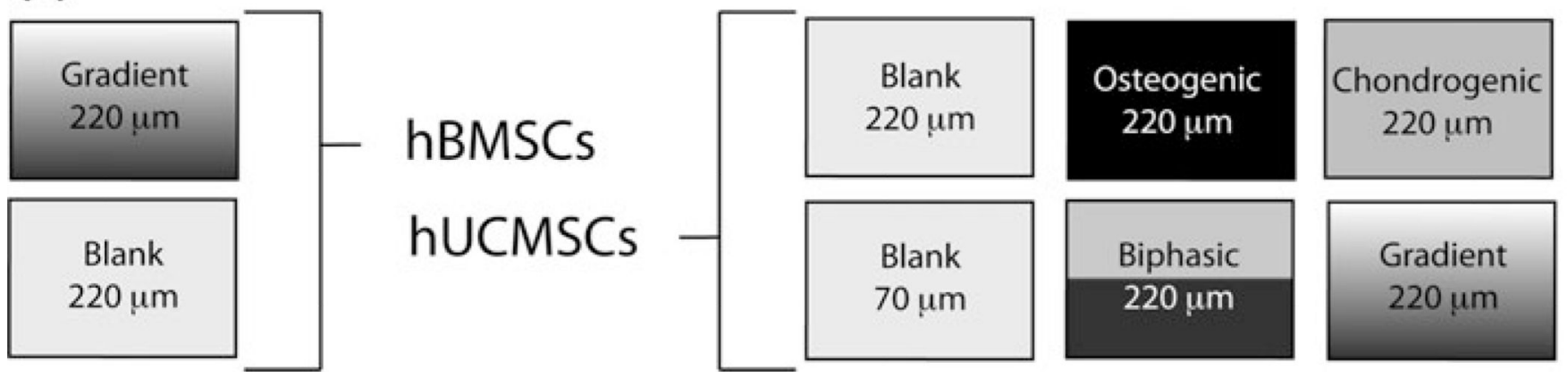

FIGURE 1.

Microparticle and scaffold fabrication process. (a) Microspheres were made from a polymer stream (20\% w/v PLGA in DCM) and annular carrier stream (0.5\% w/v PVA in $\left.\mathrm{ddH}_{2} \mathrm{O}\right)$ with an ultrasonic transducer; (b) Programmable pumps created a gradient in microsphere types based on a time-dependent process; (c) Experimental groups and particle sizes for hBMSCs and hUCMSCs. 


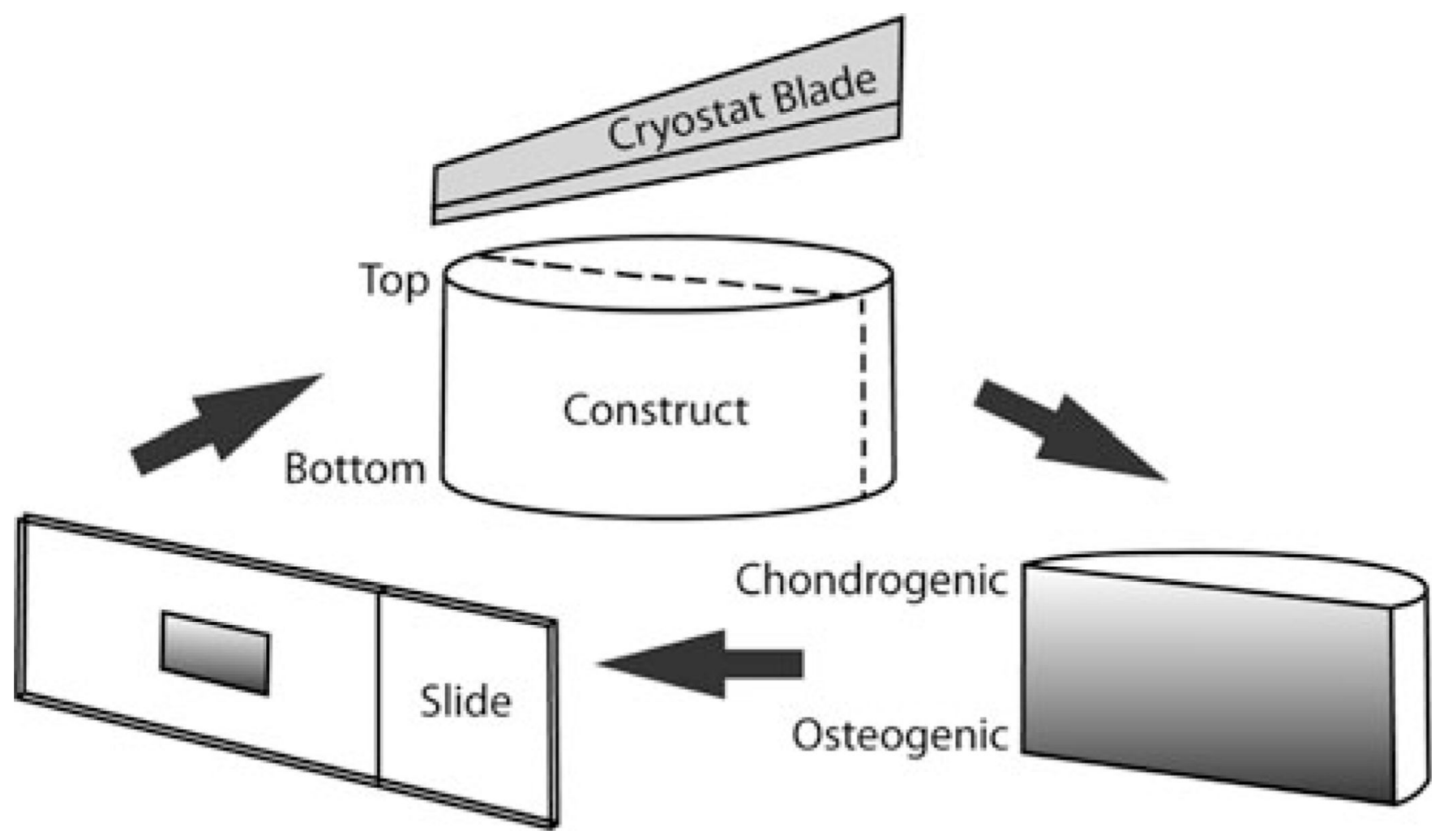

FIGURE 2.

Sectioning and orienting construct slices. Constructs were placed in culture with the "chondrogenic" side upwards and the "osteogenic" side towards the well plate surface. This orientation was maintained throughout the harvesting and histological procedure and for photo orientation. 


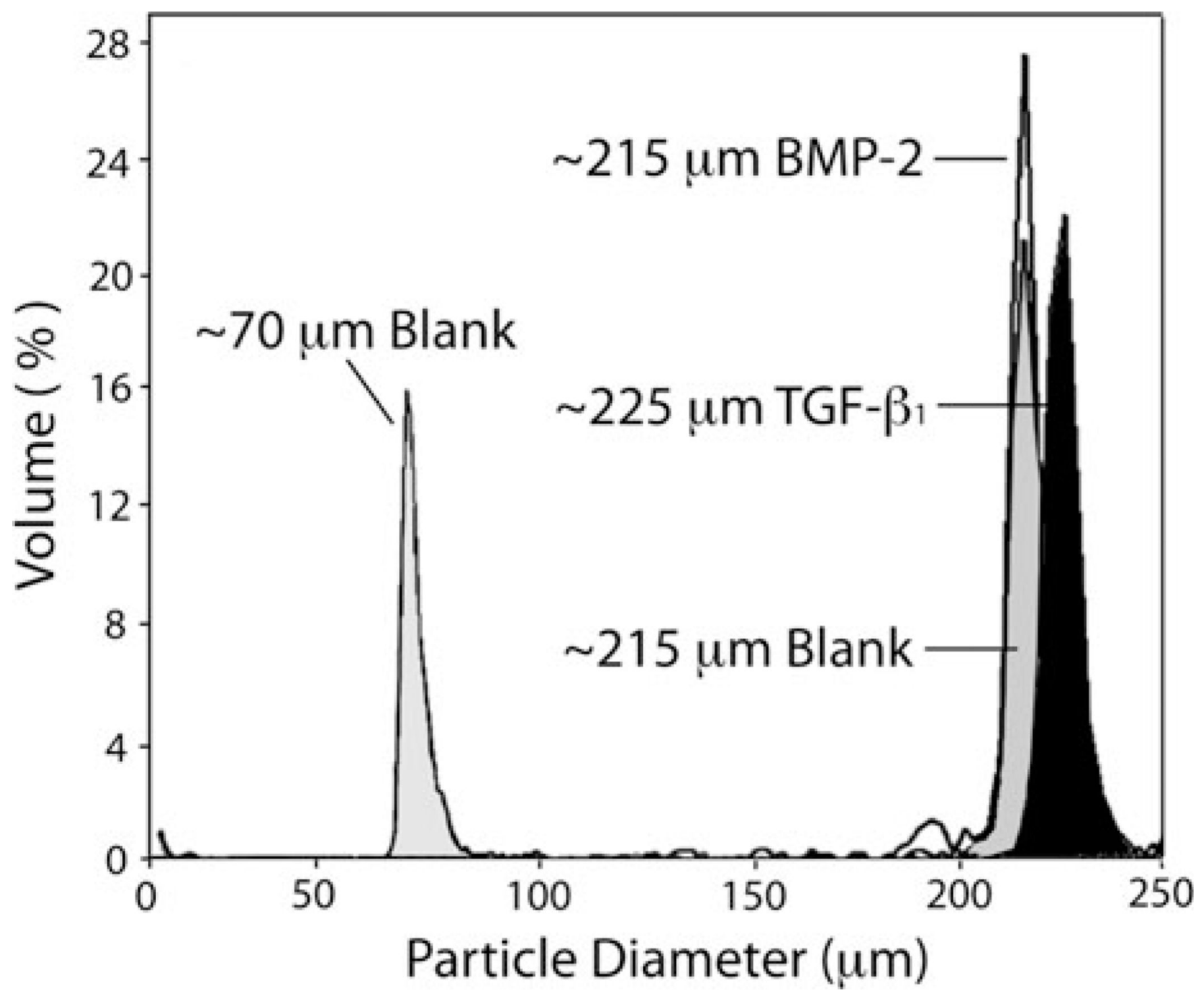

FIGURE 3.

Size characterizations for microparticles. Using a multisizer, fabricated particle batches were checked to confirm size distribution. The average diameter of all larger microspheres was approximately $220 \mu \mathrm{m}$ (BMP-2-loaded and Blank 220 Groups $\sim 215 \mu \mathrm{m}$, TGF- $\beta_{1}$-loaded $\sim 225 \mu \mathrm{m}$ ), while the smaller microspheres measured near $70 \mu \mathrm{m}$. 
(a)

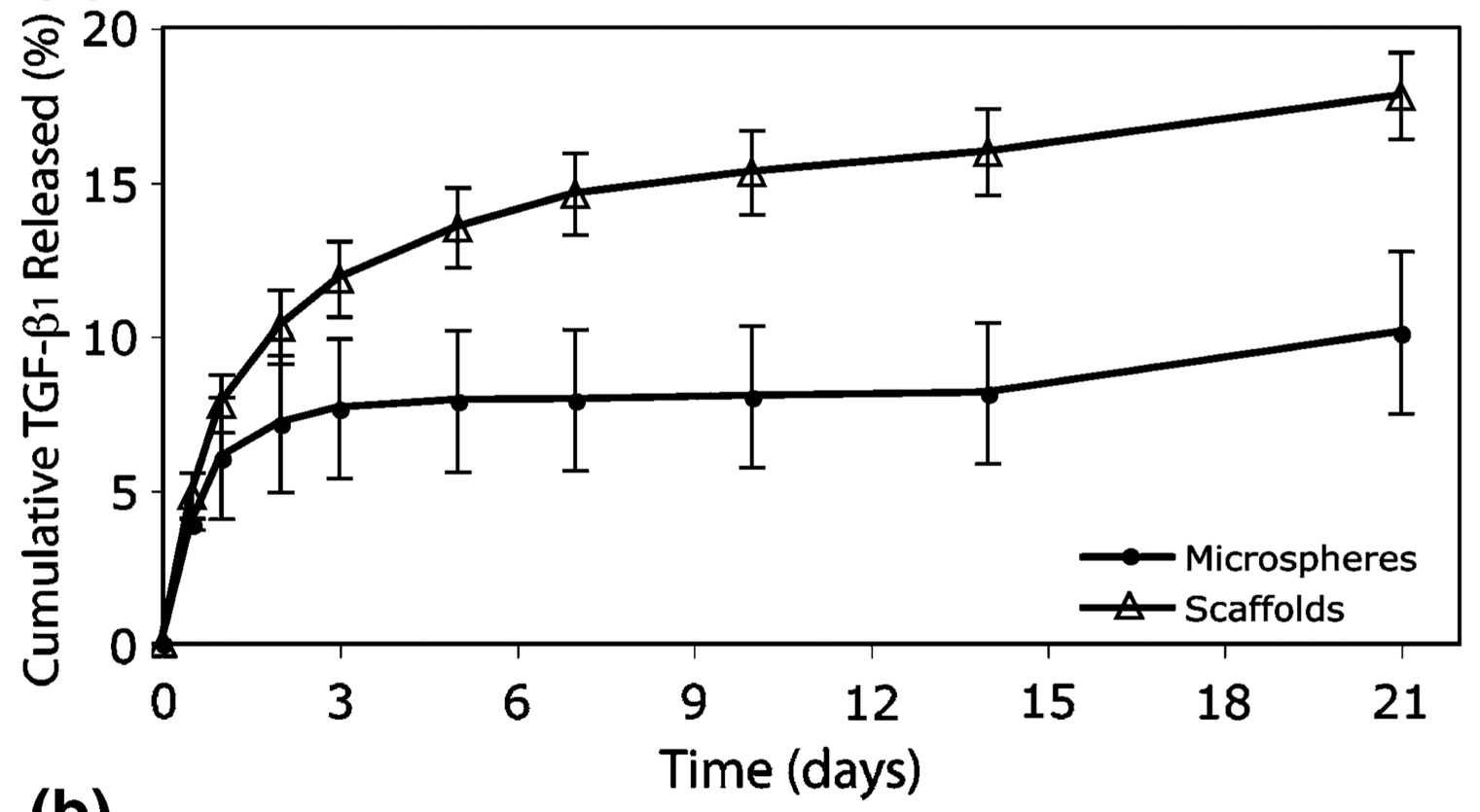

(b)

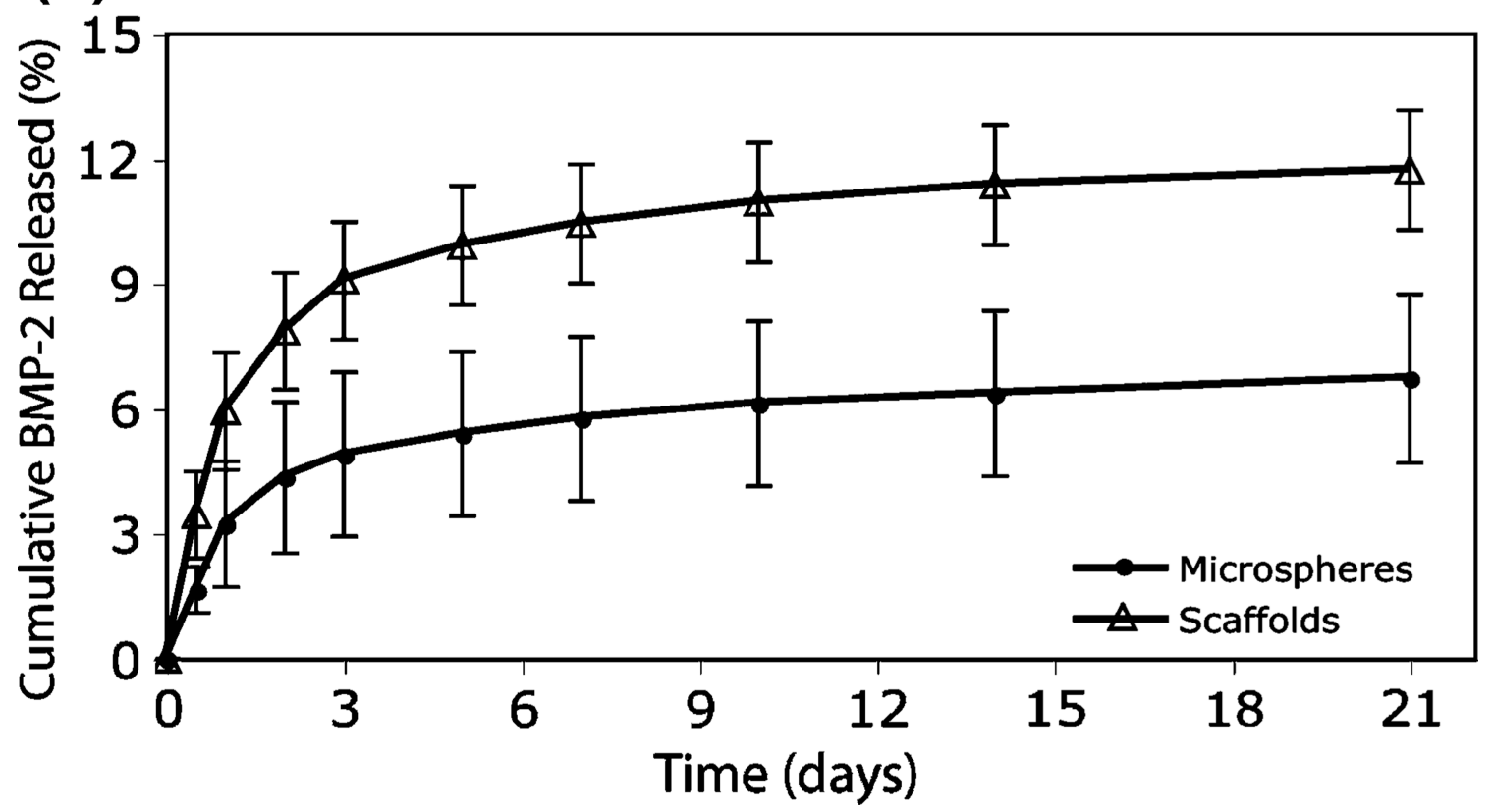

FIGURE 4.

Protein release from PLGA constructs. Release samples were taken at $12 \mathrm{~h}$, and 1, 2, 3, 5, 7, 10,14 , and 21 days for (a) TGF- $\beta_{1}$ and (b) BMP-2 microparticles and scaffolds. Percent released was calculated from the total amount of detected protein entrapped. Scaffolds showed an accelerated release profile compared to microspheres, and the onset of the third phase of release is evident at day 21 . Values are reported as mean \pm standard deviation, $n=$ 3 . 
(a)

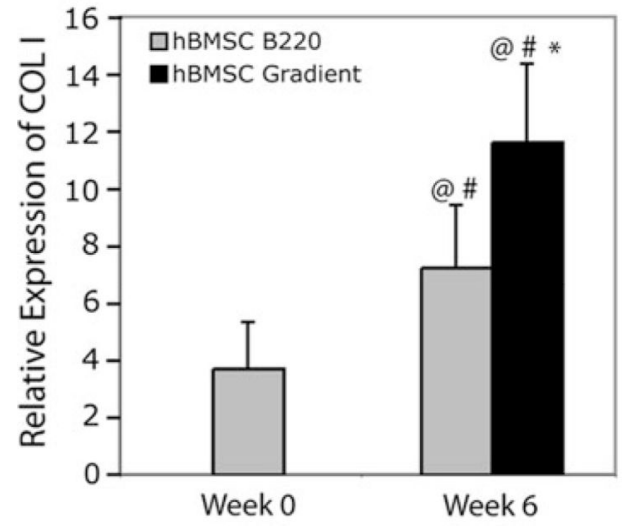

(b)

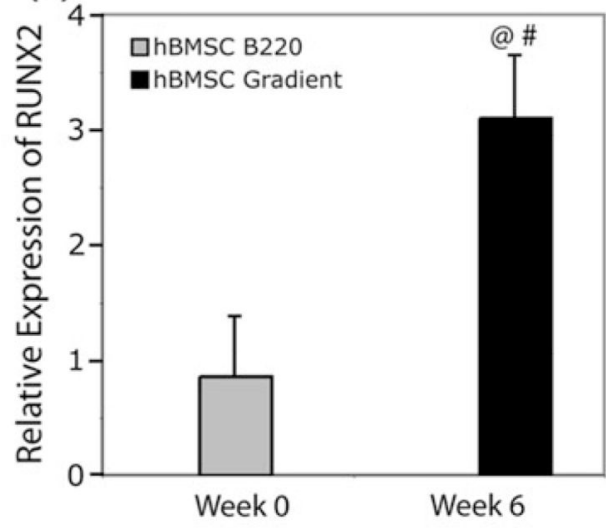

(c)

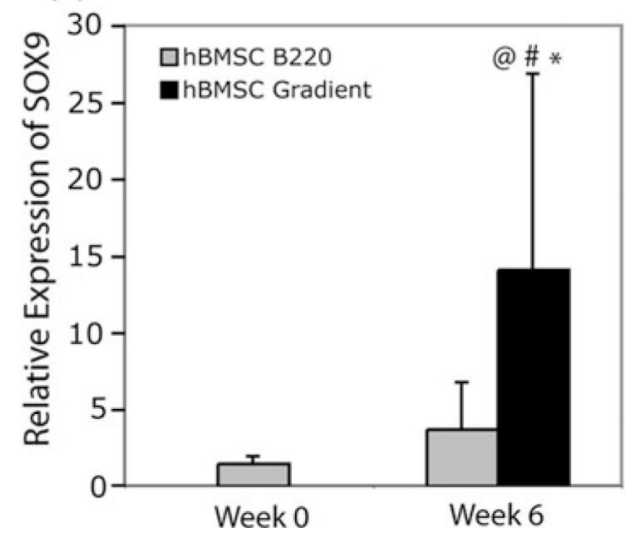

FIGURE 5.

Gene expression of collagen type I, Runx2, and Sox 9 in hBMSC constructs. Gradient constructs enhanced gene expression of (a) collagen type I, and (c) Sox9 at 6 weeks. Runx 2 expression (b) was not evident in hBMSC Blank 220 constructs at 6 weeks, whereas it was in Gradient groups. Values are reported as mean \pm standard deviation, $n=4$. Statistically significant change of expression @ = over the calibrator (hUCMSC Blank 220) at that time point $(p<0.05)$, \# = over its value at the previous time point $(p<0.05)$, and $*=$ over the control (Blank 220) at that time point $(p<0.05)$. 


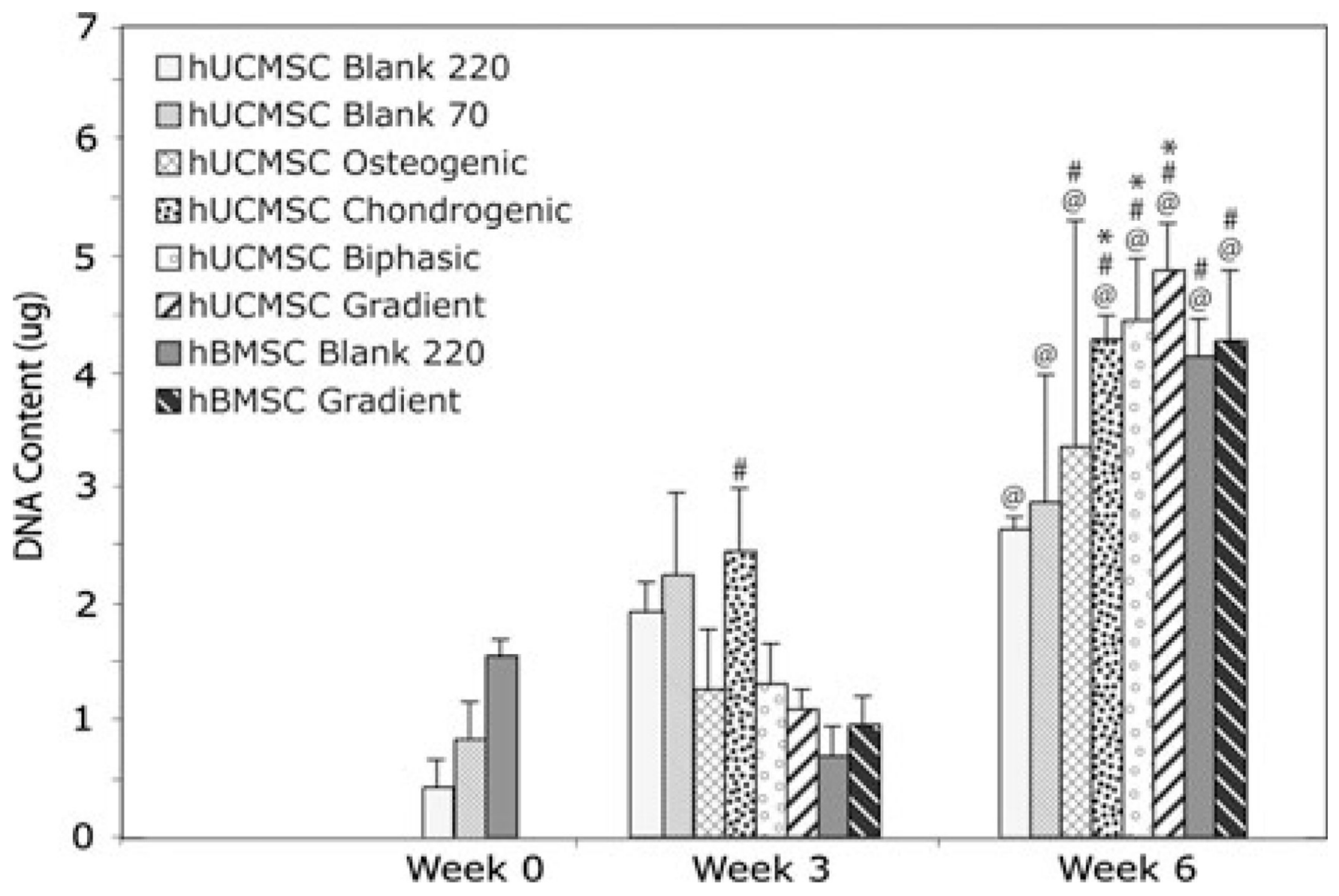

FIGURE 6.

DNA content for all hUCMSC and hBMSC groups at 0,3 , and 6 weeks. All groups had statistically significant increases over the week 0 cell number by 6 weeks, hUCMSC growth factor groups and all hBMSC groups had statistically significant increases over the week 3 values, and select hUCMSC growth factor constructs had significantly higher values compared to the control at 6 weeks (hUCMSC Blank 220). Values are reported as mean \pm standard deviation, $n=4$. Statistically significant change $@=$ over the week 0 value (Blank 220) $(p<0.05), \#=$ over its value at the previous time point $(p<0.05)$, and $*=$ over the control (Blank 220) at that time point $(p<0.05)$. 
(a)

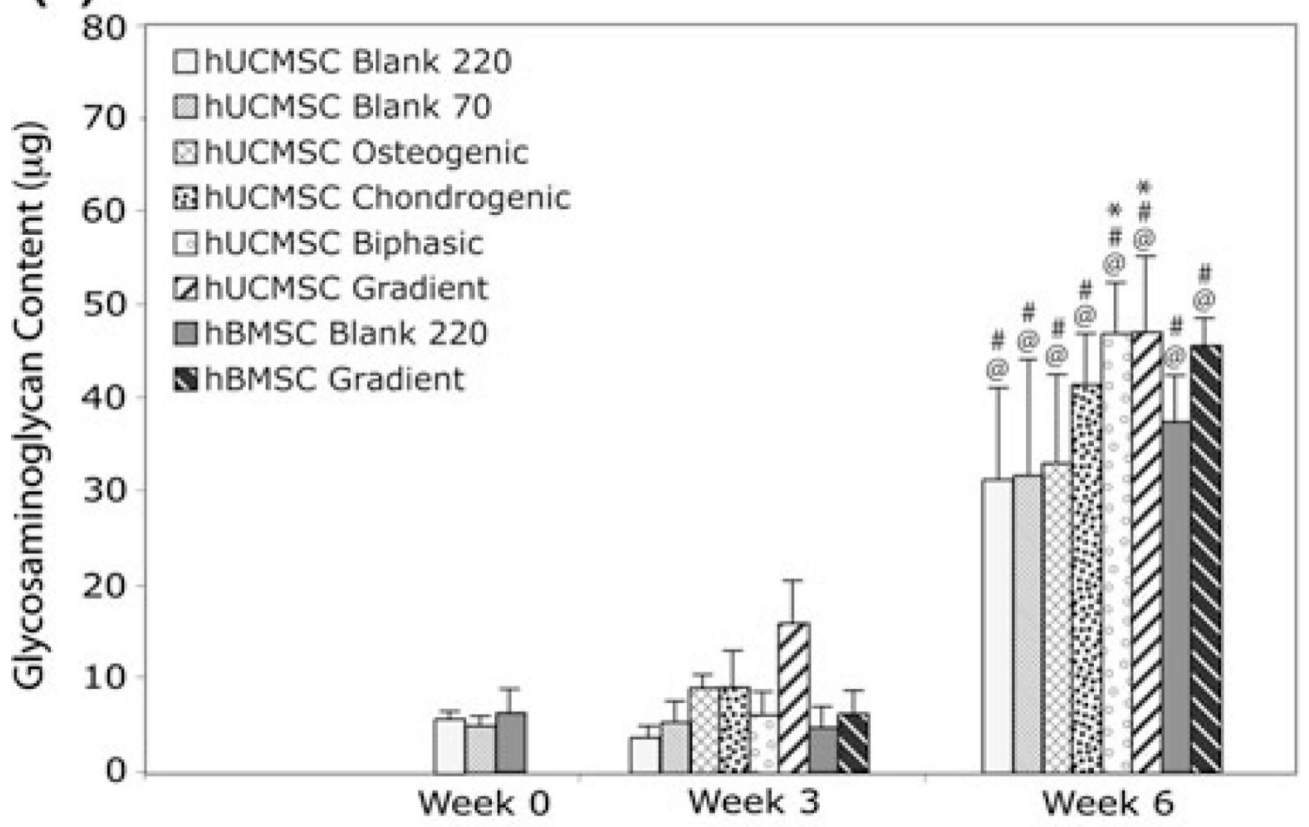

(b)

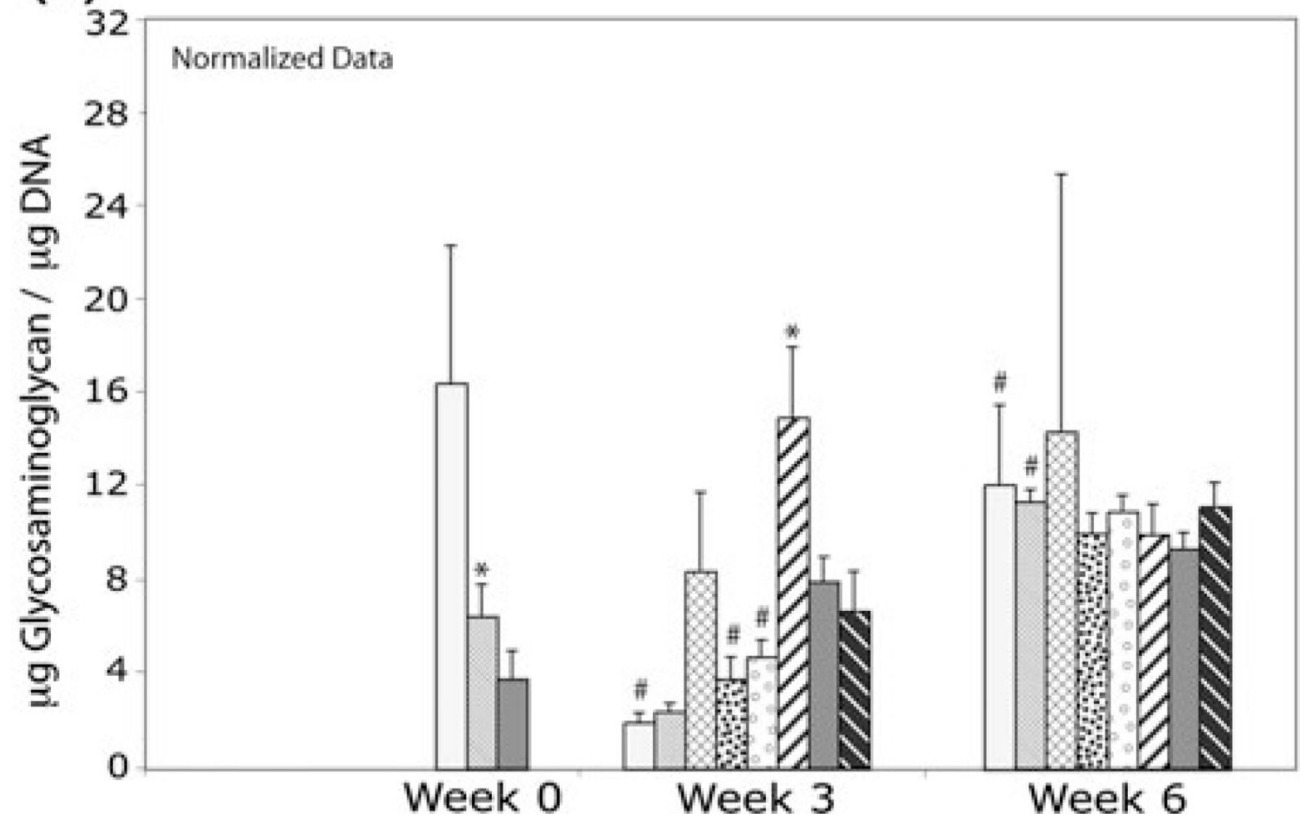

FIGURE 7.

GAG content for all hUCMSC and hBMSC groups at 0,3, and 6 weeks. (a) At 6 weeks, all groups had statistically significant increases in GAG content over the week 0 and week 3 values. Only hUCMSC Biphasic and Gradient constructs had significantly higher GAG content compared to the control at 6 weeks. (b) hUCMSC on Blank 70 scaffolds had a diminished GAG/DNA at week 0, and hUCMSC Gradient constructs had increased GAG/ DNA production over the control at 3 weeks. Values are reported as mean \pm standard deviation, $n=4$. Statistically significant change @ = over the week 0 value (Blank 220) $(p<$ $0.05)$, \# = over its value at the previous time point $(p<0.05)$, and $*=$ over the control (Blank 220) at that time point $(p<0.05)$. 
(a)

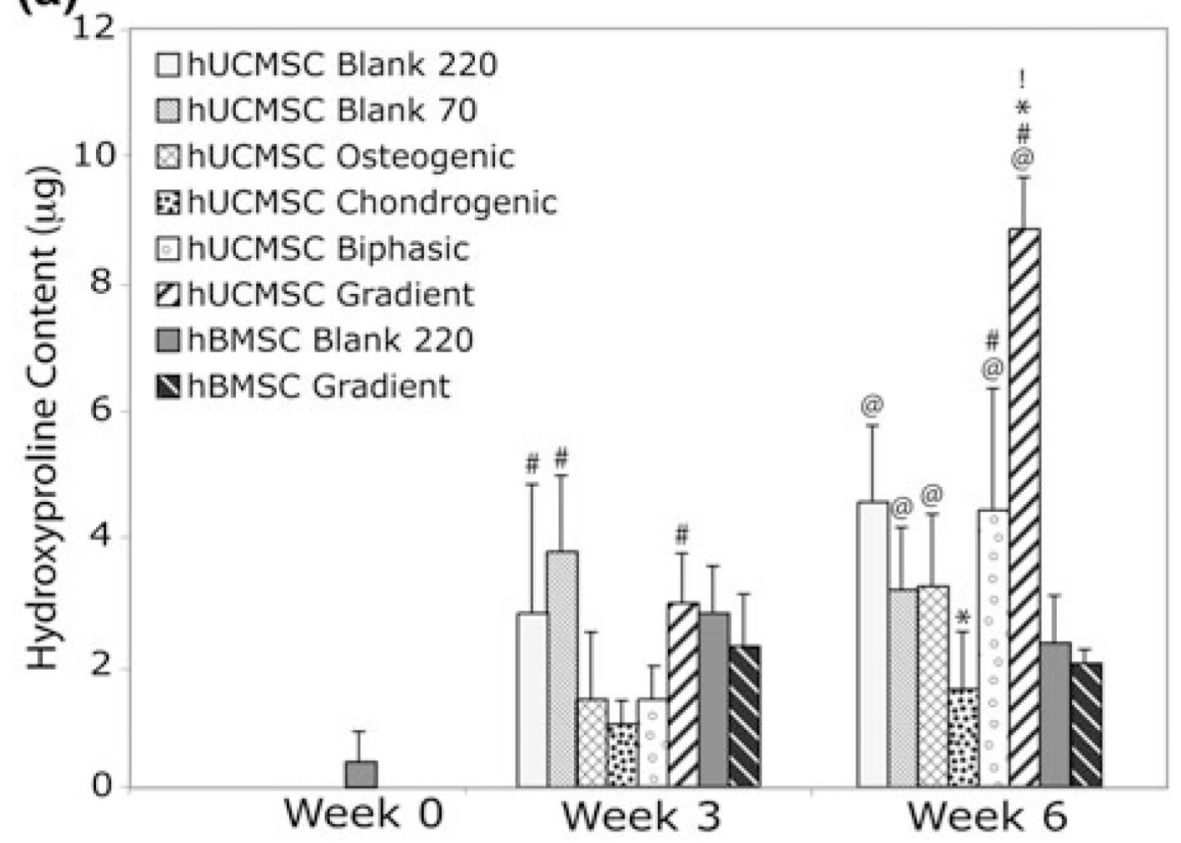

(b)

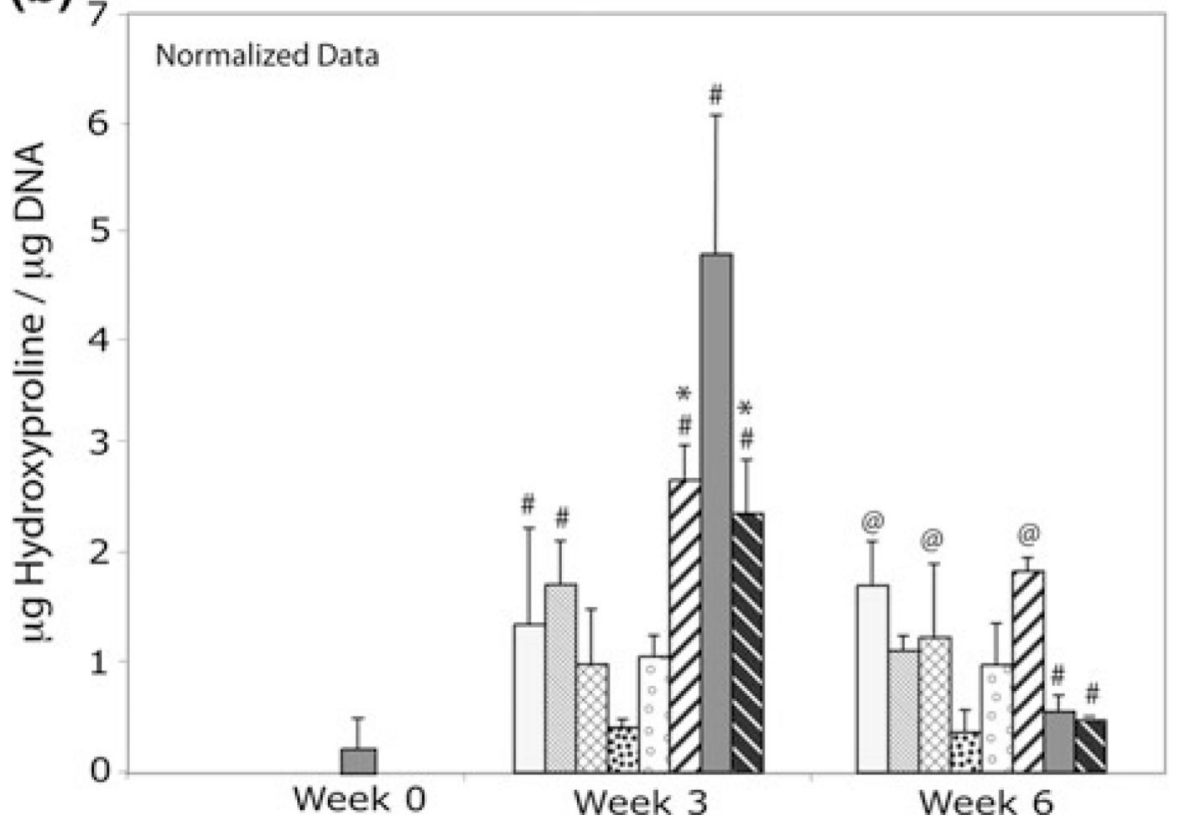

FIGURE 8.

Net hydroxyproline production for all hUCMSC and hBMSC groups at 0,3 , and 6 weeks. (a) Most hUCMSC groups had statistically significant increases in hydroxyproline from week 0 to week 6 , but only hUCMSC Gradient constructs had significantly higher production relative to the control at 6 weeks. Notably, this value was at least 2 times higher than any other group at the end of culture. At 6 weeks, the hUCMSC Chondrogenic group also showed a statistical decrease in net hydroxyproline compared to the Blank 220 group at 6 weeks. (b) hUCMSC Gradient constructs produced more HYP/DNA than the control at 3 weeks, although by 6 weeks the levels were not different from the control. Values are reported as mean \pm standard deviation, $n=4$. Statistically significant change $@=$ over the 
week 0 value (Blank 220) $(p<0.05)$, \# = over its value at the previous time point $(p<0.05)$, $*=$ over the control (Blank 220) at that time point $(p<0.05)$, and $!=$ over any other group at that timepoint $(p<0.05)$. 


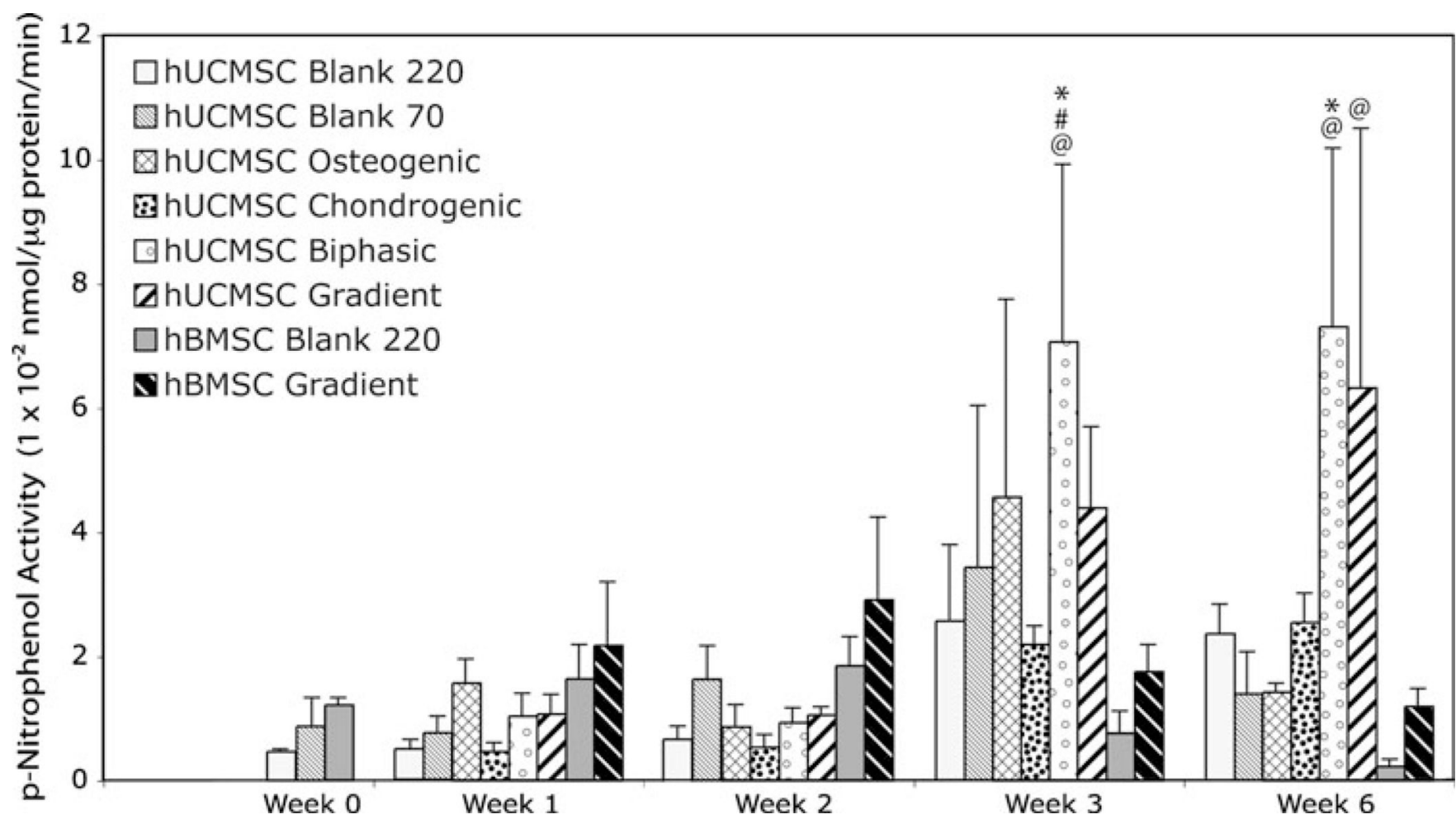

FIGURE 9.

Alkaline phosphatase activity of all hUCMSC and hBMSC constructs at $0,1,2,3$, and 6 weeks. Only the hUCMSC Biphasic groups showed increases after week 2. Values are reported as mean \pm standard deviation, $n=4$. Statistically significant change $@=$ over the week 0 value (Blank 220) $(p<0.05)$, \# = over its value at the previous time point $(p<0.05)$, and $*=$ over the control (Blank 220) at that time point $(p<0.05)$. 


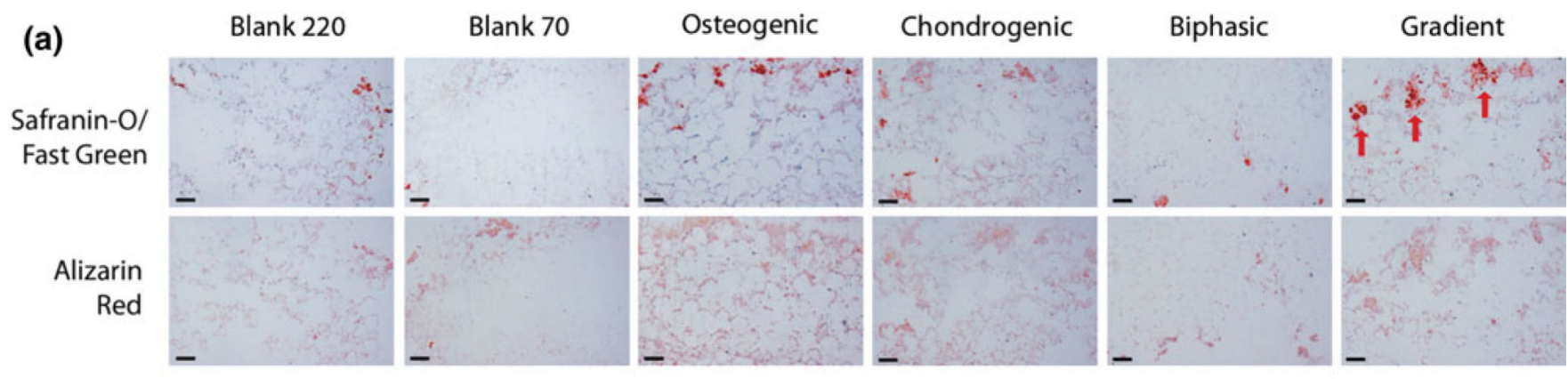

(b)

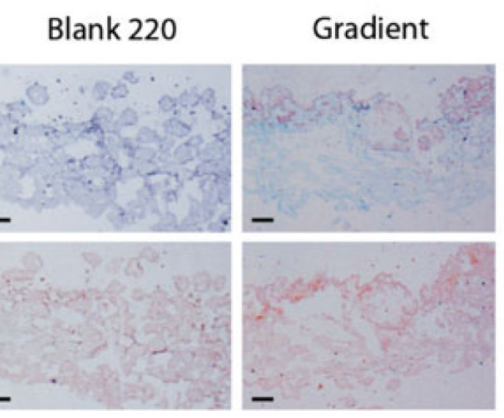

FIGURE 10.

Histological staining (Safranin-O/Fast Green and Alizarin Red) of constructs at 6 weeks. Orientation is detailed in Fig. 2 (for biphasic and gradient groups, the chondrogenic side is the top, and the osteogenic side is the bottom). (a) hUCMSC growth-factor constructs showed significantly more GAG formation and calcium deposition. hUCMSC Gradient constructs had GAG formation localized to the scaffold top (red arrows). hUCMSC Osteogenic groups appeared to have more homogenous calcium deposition than any other group. (b) hBMSC Blank 220 scaffolds had little GAG formation and even calcium deposition, whereas the Gradient group had light GAG staining localized to the scaffold top, which dissipated towards the center. Scale bar $=200 \mu \mathrm{m}$. 